\title{
The Synthesis of Magnetic Nitrogen-Doped Graphene Oxide Nanocomposite for the Removal of Reactive Orange 12 Dye
}

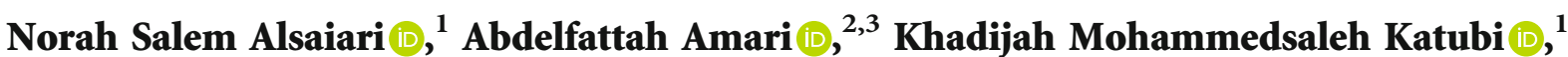 \\ Fatimah Mohammed Alzahrani $\mathbb{D},{ }^{1}$ Faouzi Ben Rebah ${ }^{(\mathbb{D})},{ }^{4}$ and Mohamed A. Tahoon $(\mathbb{D})^{5,6}$
}

${ }^{1}$ Department of Chemistry, College of Science, Princess Nourah bint Abdulrahman University, P.O. Box 84428, Riyadh 11671, Saudi Arabia

${ }^{2}$ Department of Chemical Engineering, College of Engineering, King Khalid University, Abha 61411, Saudi Arabia

${ }^{3}$ Department of Chemical Engineering, Research Laboratory of Energy and Environment, National School of Engineers, Gabes University, Gabes 6072, Tunisia

${ }^{4}$ Higher Institute of Biotechnology of Sfax (ISBS), Sfax University, P.O. Box 263, Sfax 3000, Tunisia

${ }^{5}$ Department of Chemistry, College of Science, King Khalid University, P.O. Box 9004, Abha 61413, Saudi Arabia

${ }^{6}$ Chemistry Department, Faculty of Science, Mansoura University, Mansoura 35516, Egypt

Correspondence should be addressed to Fatimah Mohammed Alzahrani; fmalzahrani@pnu.edu.sa

Received 19 November 2021; Revised 7 December 2021; Accepted 28 December 2021; Published 18 January 2022

Academic Editor: Hesham Hamad

Copyright (C) 2022 Norah Salem Alsaiari et al. This is an open access article distributed under the Creative Commons Attribution License, which permits unrestricted use, distribution, and reproduction in any medium, provided the original work is properly cited.

\begin{abstract}
Herein, we report the nanofabrication of magnetic calcium ferrite $\left(\mathrm{CaFe}_{2} \mathrm{O}_{4}\right)$ with nitrogen-doped graphene oxide (N-GO) via facile ultrasonication method to produce $\mathrm{CaFe}_{2} \mathrm{O}_{4} / \mathrm{N}-\mathrm{GO}$ nanocomposite for the potential removal of reactive orange 12 (RO12) dye from aqueous solution. The successful construction of the nanocomposite was confirmed using different characterization techniques including scanning electron microscopy (SEM), transmission electron microscopy (TEM), Fourier transform-infrared spectroscopy (FT-IR), and X-ray diffraction (XRD). The magnetic properties were studied using vibrating sample magnetometer (VSM) indicating ferromagnetic behavior of the synthesized materials that facilitate their separation using an external magnetic field after adsorption treatment. The addition of $\mathrm{N}-\mathrm{GO}$ to $\mathrm{CaFe}_{2} \mathrm{O}_{4}$ nanoparticles enhanced the BET surface area from 24 to $52.93 \mathrm{~m}^{2} / \mathrm{g}$ as resulted from the $\mathrm{N}_{2}$ adsorption-desorption isotherm. The adsorption of the synthesized nanomaterials is controlled by several parameters (initial concentration of dye, contact time, adsorbent dosage, and $\mathrm{pH}$ ), and the $\mathrm{RO} 12$ dye removal on the surface of $\mathrm{CaFe}_{2} \mathrm{O}_{4}$ nanoparticles and $\mathrm{CaFe}_{2} \mathrm{O}_{4} / \mathrm{N}$-GO nanocomposite was reached through the chemisorption process as indicated from the kinetic study. The adsorption isotherm study indicated that the adsorption process of $\mathrm{RO} 12$ dye was best described through the Langmuir isotherm approving the monolayer adsorption. According to the Langmuir model, the maximum adsorption capacity for $\mathrm{RO} 12$ was 250 and $333.33 \mathrm{mg} / \mathrm{g} \mathrm{for} \mathrm{CaFe}_{2} \mathrm{O}_{4}$ nanoparticles and $\mathrm{CaFe}_{2} \mathrm{O}_{4} / \mathrm{N}-\mathrm{GO}$ nanocomposite, respectively. The adsorption capacity offered by $\mathrm{CaFe}_{2} \mathrm{O}_{4} / \mathrm{N}-\mathrm{GO}$ nanocomposite was higher than reported in the literature for adsorbent materials. Additionally, the regeneration study indicated that $\mathrm{CaFe}_{2} \mathrm{O}_{4} / \mathrm{N}-\mathrm{GO}$ nanocomposite is reusable and cost-effective adsorbent. Therefore, the nanofabricated $\mathrm{CaFe}_{2} \mathrm{O}_{4} /$ $\mathrm{N}-\mathrm{GO}$ hybrid material is a promising adsorbent for water treatment.
\end{abstract}

\section{Introduction}

Water is essential for human, plant, and animal life alike. From an environmental point of view, the water pollution causes concerns worldwide [1]. The environmental pollution causes about $25.0 \%$ of human diseases as stated by the
World Health Organization (WHO) [2]. Dye wastewater is responsible for one of the major environmental pollution problems and represents about $20.0 \%$ of the industrial wastewater pollution as stated by the World Bank (WB) [2]. Dyes cause harmful effects on the environment and humans due to its carcinogenic, toxic, and mutagenic nature 
[3]. Various synthetic dyes are used heavily in different industries (textile, pharmaceutical, leather, food, printing, and paper industries) and discharged along with different wastewaters into the natural ecosystem causing the human organs' toxicity [4]. The most serious problem of these dyes is their nonbiodegradable nature due to its complex chemical structure [5] that causes its accumulation inside human body. Serious problems associated to dyes pushed the scientists to find solutions for the treatment of dye wastewater. Various methods including biological treatment, anodic oxidation, oxidation, electrocoagulation, photocatalysis, flocculation/coagulation, adsorption, and membrane filtration were examined and used for the treatment of real textile and dyeing effluents [6-16]. Among the available technologies, adsorption is the most used method due to cost-effectiveness, high efficiency, and easy operation [17]. The adsorption is a procedure based on the transfer of pollutant from aqueous solution to the adsorbent. However, the using of conventional adsorbents faces many problems (insufficient hydrophilic surface, insufficient functional groups, material losses during regeneration, etc.). These problems of conventional adsorbents can be overcome by using nanomaterials with exceptional properties such as the ease synthesis, high surface area, simple functionalization, and low cost [18-20]. Dye removal was achieved using several types of materials included carbonaceous materials such as graphene oxide (GO), carbon-nanotube (CNT), and activated carbon [21-23] due to its large surface area. Among all carbonaceous materials, GO is the widely used carbon-based nanomaterials for the removal of dyes due to its fluorescence quenching properties, easy surface modification, and good water solubility. Additionally, GO has several oxygencontaining groups such as $\mathrm{CO}, \mathrm{OH}$, and $\mathrm{COOH}$ that represent about $60.0 \%$ of its surface and act as claws for capturing different pollutants. Moreover, hydrophilic oxygenated surface area and hydrophobic pristine graphene that are present in GO increase its surface heterogeneity and enhance its ability to bind different pollutants via hydrophobic interactions, Van der Waals interactions, electrostatic interactions, $\pi-\pi$ stacking, and H-bonding [24]. Carbon nanomaterials doping with a heteroatom like $\mathrm{N}, \mathrm{S}$, and $\mathrm{O}$ could increase its adsorption efficiency besides its surface area [25]. For instance, the adsorption capacity of reduced graphene oxide was folded 1.4 times toward the removal of 2methylanthraquinone and anthracene when doped with $\mathrm{N}$ atom as reported by Song et al. [26]. However, the advantages of GO as adsorbents, their separation from the reaction medium is a drawback that obstacles their application in water treatment applications. Interestingly, the presence of magnetic material in the adsorbents can facilitate their separation using an external magnetic field $[27,28]$. This magnetic separation could reduce the overall cost of the treatment process and allowed the adsorbent reusability for several times. Adsorption of dyes and heavy metal using magnetically separable metal ferrite nanoparticles has been reported in many studies [29-32]. The reported magnetic nanoparticles used for the pollutants removal included $\mathrm{CaFe}_{2} \mathrm{O}_{4}, \mathrm{CoFe}_{2} \mathrm{O}_{4}, \mathrm{MgFe}_{2} \mathrm{O}_{4}, \mathrm{MnFe}_{2} \mathrm{O}_{4}$, and $\mathrm{ZnFe}_{2} \mathrm{O}_{4}$. Compared to other ferrites, $\mathrm{CaFe}_{2} \mathrm{O}_{4}$ is considered the most biocompatible due to its eco-friendly and nontoxicity nature [33]. In this context, various investigations showed the successful synthesis of magnetically separable crystalline $\mathrm{CaFe}_{2} \mathrm{O}_{4}$ nanoparticles and its potential use as an adsorbent for dyes such as reactive orange 12 (RO12) dye [34-39]. Therefore, GO can be combined with other nanomaterials such as $\mathrm{CaFe}_{2} \mathrm{O}_{4}$ nanoparticles to form nanohybrid material, to remove contaminants from water efficiently.

The purpose of the current research is to investigate the behavior of calcium ferrite/nitrogen-doped graphene oxide $\left(\mathrm{CaFe}_{2} \mathrm{O}_{4} / \mathrm{N}-\mathrm{GO}\right)$ nanocomposite in the adsorption of $\mathrm{RO} 12$ dye. The produced $\mathrm{CaFe}_{2} \mathrm{O}_{4} / \mathrm{N}-\mathrm{GO}$ nanocomposite using the facile ultrasonication synthesis benefits from the advantages of each nanocomposite part and allowed the enhancement of the nanomaterial adsorption efficiency. The synthesized nanocomposite was well-characterized using familiar techniques and examined for the removal of reactive orange 12 dye (RO12) from water. The effect of different parameters on the removal of dye was explored such as the initial concentration of dye, contact time, adsorbent dosage, and $\mathrm{pH}$. Also, the experimental data were fitted using different models of isotherms and kinetics to wellunderstand the removal process.

\section{Materials and Methods}

2.1. Chemicals. All used chemicals including ferric nitrate nonahydrate $\left(\mathrm{Fe}\left(\mathrm{NO}_{3}\right)_{3} \cdot 9 \mathrm{H}_{2} \mathrm{O}\right)$, calcium nitrate tetrahydrate $\left(\mathrm{Ca}\left(\mathrm{NO}_{3}\right)_{2} \cdot 4 \mathrm{H}_{2} \mathrm{O}\right)$, citric acid, aqueous ammonia (33\%), graphite powder, sodium hydroxide, hydrochloric acid, and RO12 dye were of analytical grade and used without any modification. All solutions were prepared using distilled water.

2.2. Synthesis of $\mathrm{CaFe}_{2} \mathrm{O}_{4}$ Nanoparticles. The $\mathrm{CaFe}_{2} \mathrm{O}_{4}$ nanoparticles were synthesized via the sol-gel method [40] as described briefly in the next steps. First, $20 \mathrm{~mL}$ of distilled $\mathrm{H}_{2} \mathrm{O}$ was used to dissolve calcium nitrate tetrahydrate $\left(\mathrm{Ca}\left(\mathrm{NO}_{3}\right)_{2} \cdot 4 \mathrm{H}_{2} \mathrm{O}\right)$ and ferric nitrate nonahydrate $\left(\mathrm{Fe}\left(\mathrm{NO}_{3}\right)_{3} \cdot 9 \mathrm{H}_{2} \mathrm{O}\right)$ with a molar ratio of $1: 2$. Then, to the above mixture, we added citric acid solution under continuous stirring at $65.0^{\circ} \mathrm{C}$. After that, ammonium aqueous solution was added to the previous mixture until the $\mathrm{pH}$ value reached 7.0 at which the sol was formed. The stirring of sol was continued for 8 hours until the formation of gel. The gel was dried for 12.0 hours at $100.0^{\circ} \mathrm{C}$. The formed gel was crushed and calcinated for 3.0 hours at $300.0^{\circ} \mathrm{C}$. The formed $\mathrm{CaFe}_{2} \mathrm{O}_{4}$ nanoparticles became ready to be used in the next step.

2.3. Synthesis of Nitrogen-Doped Graphene Oxide. A facile ultrasonication method was used for the synthesis of nitrogen-doped graphene oxide (N-GO) as described in the following steps. Aqueous ammonium solution $(25 \%(v / v)$, $20 \mathrm{~mL}$ ) was used to dissolve $0.5 \mathrm{~g}$ of graphene oxide under sonication of solution for 1.0 hour at $25.0^{\circ} \mathrm{C}$. The formed black precipitate was separated by centrifugation then washed several times with distilled $\mathrm{H}_{2} \mathrm{O}$ and dried overnight 
at $60.0^{\circ} \mathrm{C}$ in oven. The obtained N-GO became ready to be used in the next step.

2.4. Synthesis of $\left(\mathrm{CaFe}_{2} \mathrm{O}_{4} / N-G O\right)$ Nanocomposite. $\mathrm{CaFe}_{2} \mathrm{O}_{4} /$ $\mathrm{N}-\mathrm{GO}$ nanocomposite was synthesized via the sonication method. $15.0 \mathrm{~mL}$ of ethyl alcohol was used to dissolve $\mathrm{CaFe}_{2} \mathrm{O}_{4}$ nanoparticles and N-GO with w/w ratio of $1: 2$ under sonication for half hours. Then, the sonication was continued for an additional 1.0 hour. The formed precipitate was separated by centrifugation and washed several times with distilled $\mathrm{H}_{2} \mathrm{O}$. Finally, the synthesized $\mathrm{CaFe}_{2} \mathrm{O}_{4} / \mathrm{N}-\mathrm{GO}$ nanocomposite was dried overnight at $60.0^{\circ} \mathrm{C}$ in an oven. Figure 1 illustrated the synthetic route of $\mathrm{CaFe}_{2} \mathrm{O}_{4} / \mathrm{N}-\mathrm{GO}$ nanocomposite.

2.5. Material Characterization. The synthesized materials were characterized using various methods. Fouriertransform infrared spectroscopy (FT-IR-6100 Jasco, Tokyo, Japan) was used to carry out FT-IR spectra in the range of $400-4000 \mathrm{~cm}^{-1}$ at room temperature and collected at a resolution of $4 \mathrm{~cm}^{-1}$. X-ray diffractometer (XRD, X' Pert Pro, PAN analytical, Almelo, The Netherlands) was employed to determine XRD using CuKa radiation $(\lambda=1.5406 \AA)$ operating at $45 \mathrm{kV}$. The diffraction intensities were recorded over the $2 \theta$ ranging from $5^{\circ}$ to $90^{\circ}$ with the constant scanning rate of $1^{\circ} \mathrm{min}^{-1}$. A vibrating sample magnetometer (Lake Shore 7410, Lake Shore (Cryotronics Inc., Westerville, $\mathrm{OH}$, USA)) was used to measure the magnetization of the nanocomposite. The morphology and size materials were determined using a scanning electronmicroscope (SEM, Quanta FEG 250, Eindhoven, The Netherlands) and a transmission electron microscope (TEM, JEOL JEM-2100 Plus, Hillsboro, USA), respectively, operated at $200 \mathrm{KV}$.

2.6. Adsorption of RO12 Dye. The $\mathrm{CaFe}_{2} \mathrm{O}_{4} / \mathrm{N}-\mathrm{GO}$ nanocomposite was investigated for the adsorption of RO12 dye. The effect of different parameters included contact time, initial dye concentration, adsorbent dosage, and $\mathrm{pH}$ value on the adsorption of RO12 dye was determined. The effect of the contact time was studied by varying the time from 10.0 to 120.0 minutes at an adsorbent dosage of $1.0 \mathrm{~g} / \mathrm{L}$, initial dye concentration $80.0 \mathrm{mg} / \mathrm{L}$, and solution $\mathrm{pH}$ of 2.0. The adsorbent dosage effect was studied in the range of $0.125-1.50 \mathrm{~g} / \mathrm{L}$ at an initial concentration of $80.0 \mathrm{mg} / \mathrm{L}$, contact time of 80.0 minutes, and $\mathrm{pH}$ equal to 2.0. The initial dye concentration effect and $\mathrm{pH}$ effect were studied in the range of 20.0 to $150.0 \mathrm{mg} / \mathrm{L}$ and 2.0 to 7.0 , respectively, at the same previous conditions. All previous adsorption experiments were repeated three times to determine the error. After each experiment, the adsorbent was collected from the reaction medium using an external magnet, and the solution was analyzed for the presence of dye using a UV-vis spectrophotometer at $\lambda_{\max }=416 \mathrm{~nm}$.

The adsorption capacity (in $\mathrm{mg} / \mathrm{g}$ ) and removal efficiency (in \%) can be calculated using eqs. (1) and (2), respectively.

$$
\text { Adsorption capacity }(q e)=\left(\frac{\left(C_{i}-C_{e}\right)}{W}\right) x V \text {. }
$$

The symbols $C_{i}, C_{e}, V$, and $W$ denote the initial concentration, equilibrium concentration, volume of solution $(\mathrm{L})$, and mass of adsorbent (g), respectively.

$$
\text { Removal efficiency }(\%)=\left(\frac{C_{i}-C_{e}}{C_{i}}\right) x 100 .
$$

The adsorption kinetics were studied using pseudo $1^{\text {st }}$ order, pseudo $2^{\text {nd }}$ order, and intraparticle diffusion models that represent by eq. (3), eq. (4), and eq. (5), respectively.

$$
\begin{aligned}
\log \left(q e-q_{t}\right) & =\log q_{e}-\left(\frac{K_{1}}{2.303}\right) t, \\
\frac{t}{q_{t}} & =\left(\frac{1}{K_{2} q_{e}^{2}}\right)+\left(\frac{1}{q_{e}}\right) t, \\
q_{t} & =K_{i d} t^{0.5}+C^{i d},
\end{aligned}
$$

where the symbols $k_{2}, k_{1}, q_{t}, q_{e}, K^{\text {id }}$, and $C^{\text {id }}$ denote pseudo $2^{\text {nd }}$ order rate constant, pseudo $1^{\text {st }}$ order rate constant, adsorption capacity $(\mathrm{mg} / \mathrm{g})$ at $t$ time, adsorption capacity at equilibrium $(\mathrm{mg} / \mathrm{g})$, intraparticle diffusion rate constant, and intraparticle diffusion constant, respectively.

The Langmuir and Freundlich adsorption isotherms models were used to study the adsorption mechanism. The Freundlich and Langmuir models can be represented by eq. (6) and eq. (7), respectively.

$$
\begin{aligned}
\ln q_{e} & =\ln K_{F}+\left(\frac{1}{n}\right) \ln C_{e}, \\
\frac{C_{e}}{q_{e}} & =\left(\frac{1}{q_{m} b}\right)+\left(\frac{C_{e}}{q_{m}}\right),
\end{aligned}
$$

where $q_{m}$ and $C_{e}$ denote maximum adsorption capacity $(\mathrm{mg} / \mathrm{g})$ and equilibrium concentration, respectively, while $n$ and $K_{F}$ denote the Freundlich constants. The reusability of $\mathrm{CaFe}_{2} \mathrm{O}_{4} / \mathrm{N}-\mathrm{GO}$ nanocomposite for the removal of $\mathrm{RO} 12$ dye was investigated up to six successive cycles using $0.1 \mathrm{M}$ of $\mathrm{HCl}$ as eluent at the optimum conditions. After each cycle, the adsorbent was collected using magnet and washed several times with $\mathrm{HCl}$ and $\mathrm{H}_{2} \mathrm{O}$ then dried in oven at $60.0^{\circ} \mathrm{C}$ for the next cycle.

\section{Results and Discussion}

3.1. Characterization of $\mathrm{CaFe}_{2} \mathrm{O}_{4} / \mathrm{N}-\mathrm{GO}$ Nanocomposite. The synthesized $\mathrm{CaFe}_{2} \mathrm{O}_{4}$ nanoparticles and $\mathrm{CaFe}_{2} \mathrm{O}_{4} / \mathrm{N}-\mathrm{GO}$ nanocomposites were characterized using familiar techniques as shown in the next section. For the determination of functional groups, FT-IR spectra were performed (Figure 2(a)). The FT-IR spectrum of $\mathrm{CaFe}_{2} \mathrm{O}_{4}$ nanoparticles showed a band at $712.2 \mathrm{~cm}^{-1}$ representing the stretching band of Fe-O. Also, the Fe-O stretching band was represented by the wide bands that appeared at 604 and 640.7 $\mathrm{cm}^{-1}$. Fe-OH bending was represented by the bands that appeared at 857.6 and $875.3 \mathrm{~cm}^{-1}$. The band that appeared at $3441 \mathrm{~cm}^{-1}$ represents the stretching vibrations of $\mathrm{OH}$ 


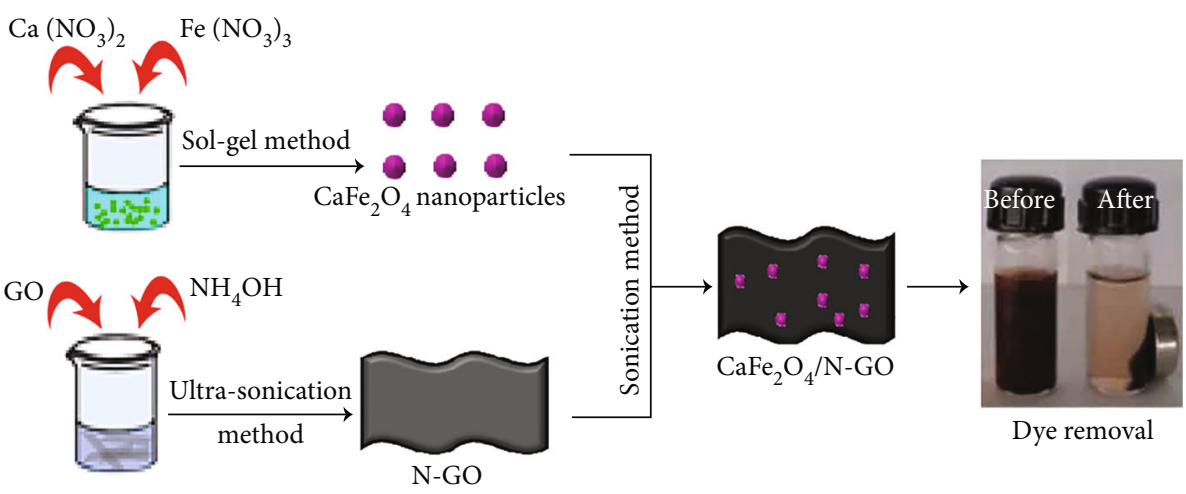

Figure 1: Schematic diagram for the synthesis $\mathrm{CaFe}_{2} \mathrm{O}_{4} / \mathrm{N}-\mathrm{GO}$ nanocomposite.

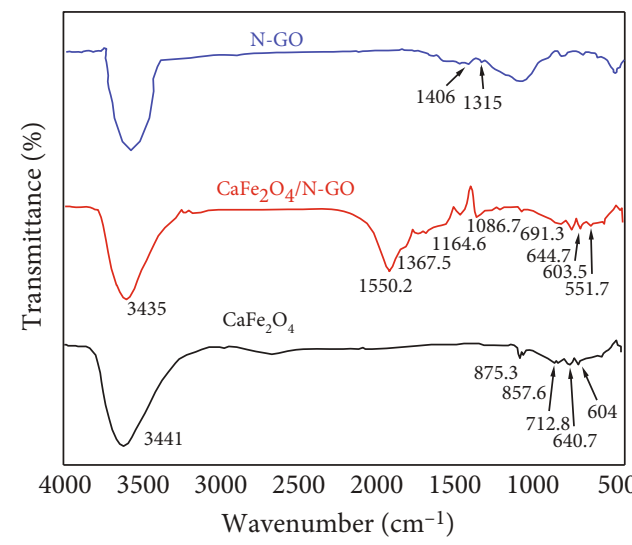

(a)

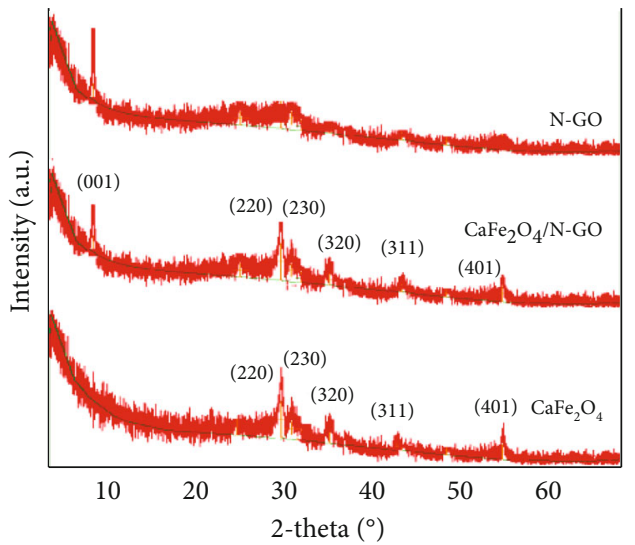

(b)

FIgure 2: FT-IR (a) and XRD (b) of the synthesized $\mathrm{CaFe}_{2} \mathrm{O}_{4}$ nanoparticles, $\mathrm{N}-\mathrm{GO}$, and $\mathrm{CaFe}_{2} \mathrm{O}_{4} / \mathrm{N}-\mathrm{GO}$ nanocomposite.

bond [34]. For the N-GO spectrum, the characteristic bands of GO are present such as the peaks at $1114 \mathrm{~cm}^{-1}$ and $3410 \mathrm{~cm}^{-1}$ that represent $\mathrm{C}-\mathrm{OH}$ stretching vibration and $\mathrm{O}-$ $\mathrm{H}$ stretching vibrations, respectively $[41,42]$. While the peak at $1315 \mathrm{~cm}^{-1}$ represented the $\mathrm{C}=\mathrm{N}$ stretching vibrations, the peak at $1406 \mathrm{~cm}^{-1}$ represented the C-N stretching vibrations, and these two peaks are evidence for nitrogen doping [42, 43]. The FT-IR spectrum of the nanocomposite showed the appearance of new absorption bands due to the C-O, C-N, and $\mathrm{C}=\mathrm{N}$ bonds that appeared at 1086.7, 1164.6, and $1367.5 \mathrm{~cm}^{-1}$, respectively, and approved the doping of $\mathrm{N}$ atom in the GO sheets. Also, the addition of N-GO sheets caused the shift of the O-H stretching band. The disappearance of the band corresponding to $\mathrm{Fe}-\mathrm{OH}$ could result from the breaking of the $\mathrm{OH}$ bond due to the interaction between the $\mathrm{COOH}$ group in the nanosheets and $\mathrm{Fe}-\mathrm{OH}$. Additionally, the interaction between the nanosheets and ferrite nanoparticles could be confirmed by the shift of the Fe-O band from 712.2 to $693 \mathrm{~cm}^{-1}$. The existence of spinel ferrite in the $\mathrm{CaFe}_{2} \mathrm{O}_{4} / \mathrm{N}-\mathrm{GO}$ nanocomposite was confirmed by the appearance of bands at 551.7 and $644.7 \mathrm{~cm}^{-1}$ that represent the vibrations of the Fe-O bond. Also, the $\mathrm{N}-\mathrm{H}$ bending vibration and $\mathrm{O}-\mathrm{H}$ stretching vibration are represented by the bands that appeared at 1550.2 and $3435 \mathrm{~cm}^{-1}$, respectively [44]. The FT-IR spectra of $\mathrm{CaFe}_{2} \mathrm{O}_{4}$ nanoparticles and $\mathrm{CaFe}_{2} \mathrm{O}_{4} / \mathrm{N}-\mathrm{GO}$ nanocomposite indicated the well construction of the nanocomposite [34, 44].

For the determination of crystal structure and phase purity of $\mathrm{CaFe}_{2} \mathrm{O}_{4}$ nanoparticles and $\mathrm{CaFe}_{2} \mathrm{O}_{4} / \mathrm{N}-\mathrm{GO}$ nanocomposite, the XRD was investigated (Figure 2(b)). According to Figure 2(b), XRD of $\mathrm{CaFe}_{2} \mathrm{O}_{4}$ nanoparticles showed the presence of (401), (311), (320), (230), and (220) planes represented by the peaks at $54.53,43.66,34.90,30.17$, and $29.57^{\circ}$, respectively, indicating the face-centered cubic lattice [45]. For XRD of N-GO, the strong diffraction peak at $2 \theta$ $=10.2^{\circ}$ can be attributed to the characteristic plane of GO. The XRD of the nanocomposite showed the appearance of the same peaks of $\mathrm{CaFe}_{2} \mathrm{O}_{4}$ nanoparticles with the appearance of an additional peak at $10.0^{\circ}$, which is resulted due to the addition of N-GO nanosheets. To study the particle morphology, TEM analysis was performed for the synthesized GO, N-GO, $\mathrm{CaFe}_{2} \mathrm{O}_{4}$ nanoparticles, and $\mathrm{CaFe}_{2} \mathrm{O}_{4} / \mathrm{N}$ GO nanocomposite as shown in Figures 3(a), 3(b), 3(c) and 3(e), respectively. According to Figure 3(a), a layered structure was observed for pristine GO while the TEM image of doped GO nanosheets (Figure 3(b)) showed an increase in the wrinkling due to the doping of nanosheets by the heteroatom. The TEM image of $\mathrm{CaFe}_{2} \mathrm{O}_{4}$ nanoparticles (Figure 3(c)) indicated that the ferrite nanoparticles have size of $10.0: 20.0 \mathrm{~nm}$ as confirmed from the size distribution 


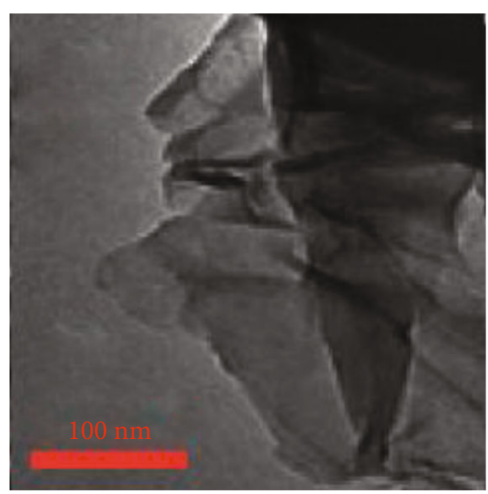

(a)

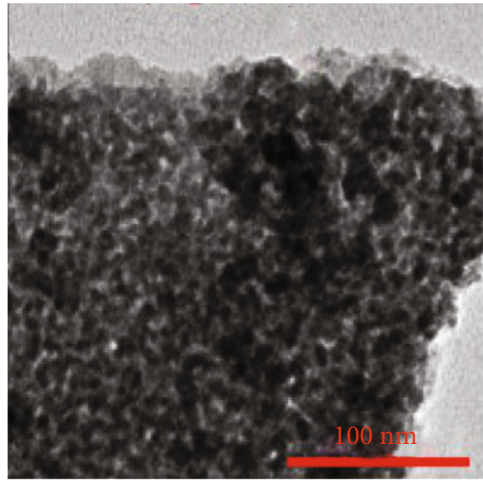

(c)

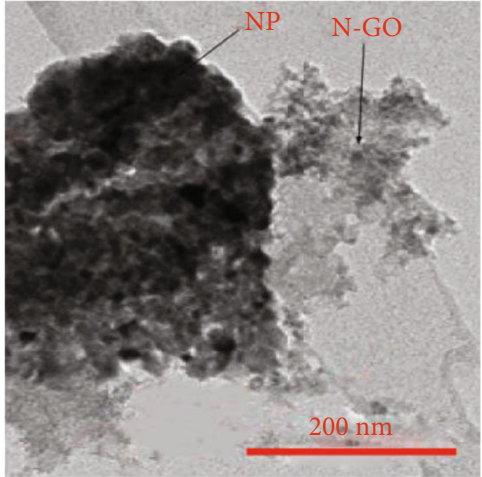

(e)

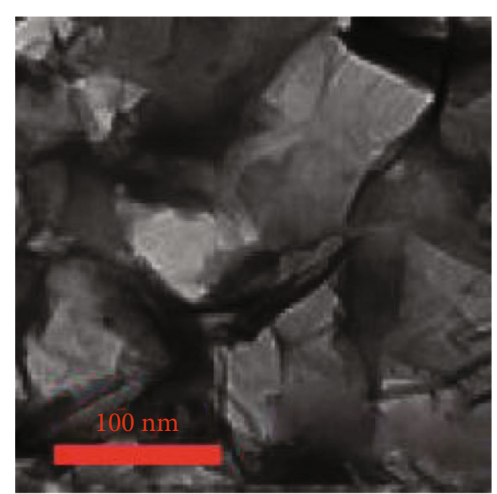

(b)

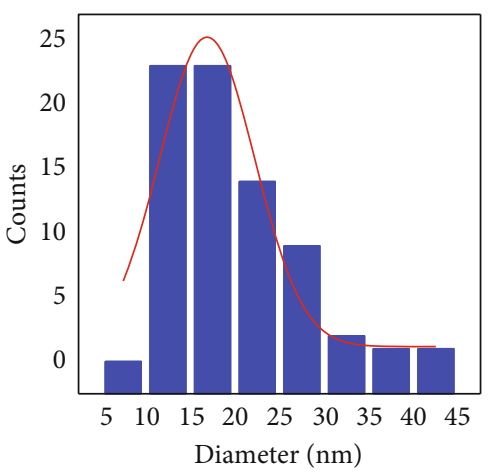

(d)

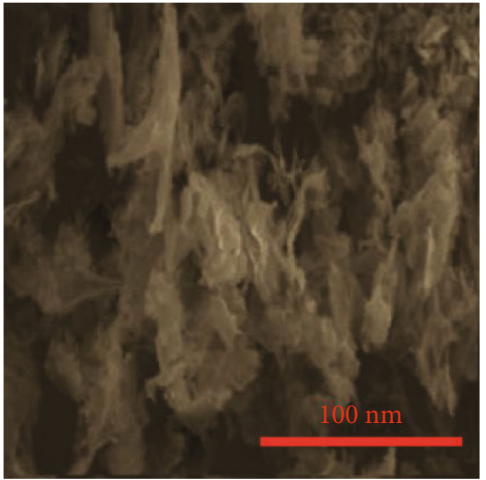

(f)

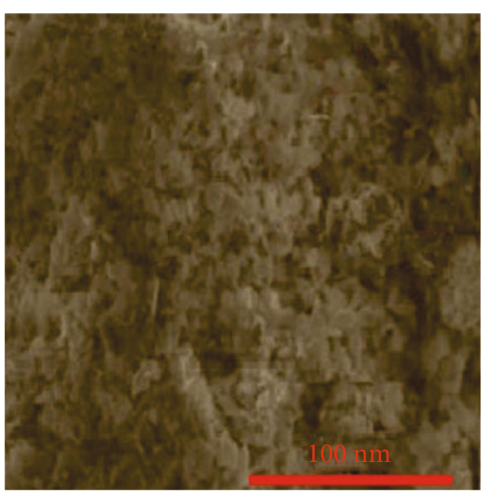

(g)

Figure 3: TEM images of GO (a), N-GO (b), $\mathrm{CaFe}_{2} \mathrm{O}_{4}$ nanoparticles (c), $\mathrm{CaFe}_{2} \mathrm{O}_{4}$ nanoparticles size histogram (d), CaFe $\mathrm{O}_{4} / \mathrm{N}-\mathrm{GO}$ nanocomposite (e), SEM images of $\mathrm{CaFe}_{2} \mathrm{O}_{4}$ nanoparticles (f), and $\mathrm{CaFe}_{2} \mathrm{O}_{4} / \mathrm{N}-\mathrm{GO}$ nanocomposite (g). 


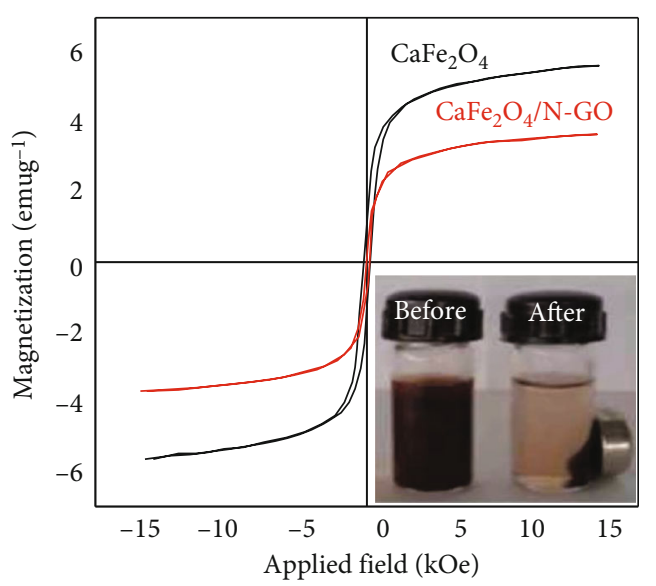

(a)

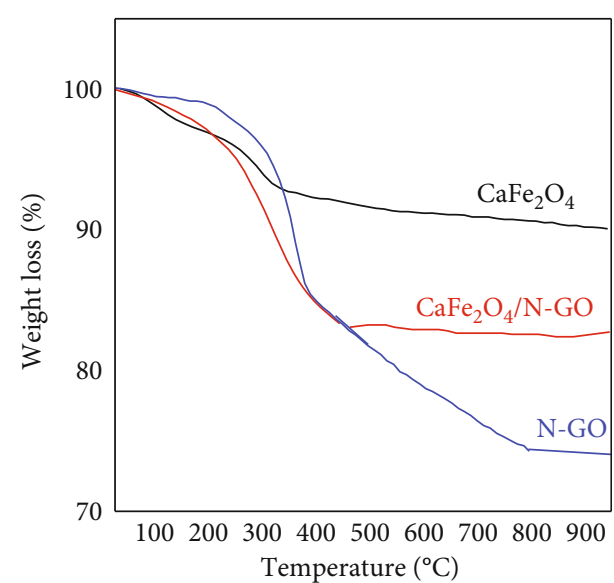

(b)

FIgure 4: Magnetization curve of the synthesized $\mathrm{CaFe}_{2} \mathrm{O}_{4}$ nanoparticles and $\mathrm{CaFe}_{2} \mathrm{O}_{4} / \mathrm{N}-\mathrm{GO}$ nanocomposite (inset: the magnetic separation of magnetic nanocomposite after dye removal) (a) and TGA curve of $\mathrm{CaFe}_{2} \mathrm{O}_{4}$ nanoparticles, $\mathrm{N}-\mathrm{GO}$, and CaFe $\mathrm{O}_{4} / \mathrm{N}-\mathrm{GO}$ nanocomposite (b).

histogram (Figure 3(d)) with an agglomeration resulted from their magnetic properties. The TEM image (Figure 3(e)) of the nanocomposite showed the distribution of ferrite nanoparticles over the nanosheets of doped GO.

To study the surface topography, the SEM analysis was performed for $\mathrm{CaFe}_{2} \mathrm{O}_{4}$ nanoparticles and $\mathrm{CaFe}_{2} \mathrm{O}_{4} / \mathrm{N}-\mathrm{GO}$ nanocomposite as shown in Figures 3(f) and 3(g), respectively. According to Figure 3(f), the synthesized ferrite nanoparticles showed agglomeration behavior resulted from the magnetic properties of the nanoparticles and confirmed the results of TEM analysis. The SEM image of $\mathrm{CaFe}_{2} \mathrm{O}_{4} / \mathrm{N}$ GO nanocomposite (Figure 3(g)) showed a great difference while compared to the SEM image of the nanoparticles illustrated by an increase in the surface roughness designating the distribution of calcium ferrite nanoparticles on the surface of doped nanosheets. Because the magnetic separation of any adsorbent after the treatment is an important advantage of the adsorption process, the magnetic properties of the synthesized $\mathrm{CaFe}_{2} \mathrm{O}_{4}$ nanoparticles and $\mathrm{CaFe}_{2} \mathrm{O}_{4} / \mathrm{N}-\mathrm{GO}$ nanocomposite were investigated using VSM with applied field range from $-15 \mathrm{KOe}$ to $15 \mathrm{KOe}$ as shown in Figure 4(a). According to Figure 4(a), the $\mathrm{CaFe}_{2} \mathrm{O}_{4}$ nanoparticles and $\mathrm{CaFe}_{2} \mathrm{O}_{4} / \mathrm{N}-\mathrm{GO}$ nanocomposite showed ferromagnetic behavior, which is clear from the s-shaped hysteresis loops. The saturation magnetization $\left(\mathrm{M}_{\mathrm{S}}\right)$ of the $\mathrm{CaFe}_{2} \mathrm{O}_{4}$ nanoparticles is $5.82 \mathrm{emug}^{-1}$ while this value was dropped to $3.05 \mathrm{emug}^{-1}$ after the addition of N-GO nanosheets. This drop was due to the nonmagnetic behavior of the doped nanosheets that cause quenching of magnetic moment and decrease the magnetic permeability of the material. The magnetic properties of the synthesized $\mathrm{CaFe}_{2} \mathrm{O}_{4} / \mathrm{N}-\mathrm{GO}$ nanocomposite helped in the magnetic separation of the nanocomposite, after dye adsorption, using an external magnet as shown in Figure 4(a) (inset).

To study the thermal properties of the synthesized materials $\mathrm{CaFe}_{2} \mathrm{O}_{4}$ nanoparticles, N-GO, and $\mathrm{CaFe}_{2} \mathrm{O}_{4} / \mathrm{N}-\mathrm{GO}$ nanocomposite, the thermogravimetric analysis (TGA) was used as shown in Figure 4(b). For $\mathrm{CaFe}_{2} \mathrm{O}_{4}$ nanoparticles,

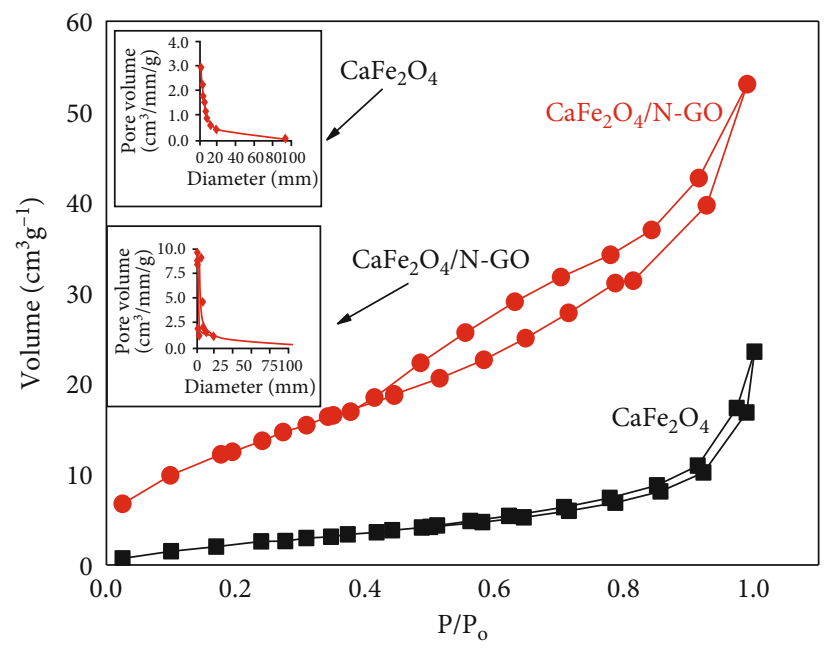

FIGURE 5: $\mathrm{N}_{2}$ adsorption-desorption isotherm of the synthesized $\mathrm{CaFe}_{2} \mathrm{O}_{4}$ nanoparticles and $\mathrm{CaFe}_{2} \mathrm{O}_{4} / \mathrm{N}-\mathrm{GO}$ nanocomposite.

TABLE 1: The determined surface area, pore diameter, and pore volume of $\mathrm{CaFe}_{2} \mathrm{O}_{4}$ nanoparticles and $\mathrm{CaFe}_{2} \mathrm{O}_{4} / \mathrm{N}-\mathrm{GO}$ nano composite using BET study.

\begin{tabular}{lccc}
\hline Material & $\begin{array}{c}S_{\mathrm{BET}} \\
\left(\mathrm{m}^{2} \cdot \mathrm{g}^{-1}\right)\end{array}$ & $\begin{array}{c}\text { Pore diameter } \\
(\mathrm{nm})\end{array}$ & $\begin{array}{c}\text { Pore volume } \\
\left(\mathrm{cm}^{3} \cdot \mathrm{g}^{-1}\right)\end{array}$ \\
\hline $\mathrm{CaFe}_{2} \mathrm{O}_{4} / \mathrm{N}-\mathrm{GO}$ & 52.93 & 3.46 & 0.045 \\
$\mathrm{CaFe}_{2} \mathrm{O}_{4}$ & 24.0 & 3.25 & 0.034 \\
\hline
\end{tabular}

N-GO, and $\mathrm{CaFe}_{2} \mathrm{O}_{4} / \mathrm{N}-\mathrm{GO}$ nanocomposite, the slight weight loss that occurred below $100^{\circ} \mathrm{C}$ was attributed to the evaporation of physically adsorbed water molecules. For N-GO, the weight loss at temperature between 120 and $220^{\circ} \mathrm{C}$ was attributed to the decomposition of different functional groups while at higher temperature; the weight loss was attributed to the decomposition of carbon skeleton. For $\mathrm{CaFe}_{2} \mathrm{O}_{4}$ nanoparticles, the TGA curve indicates their thermal stability with no notable weight loss with 


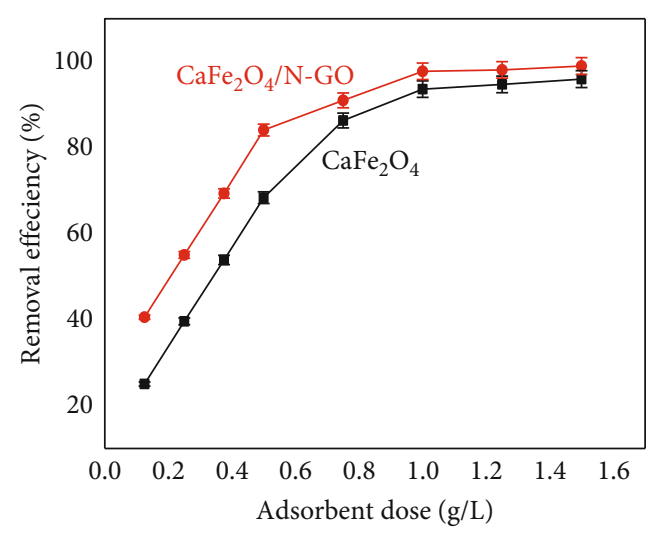

(a)

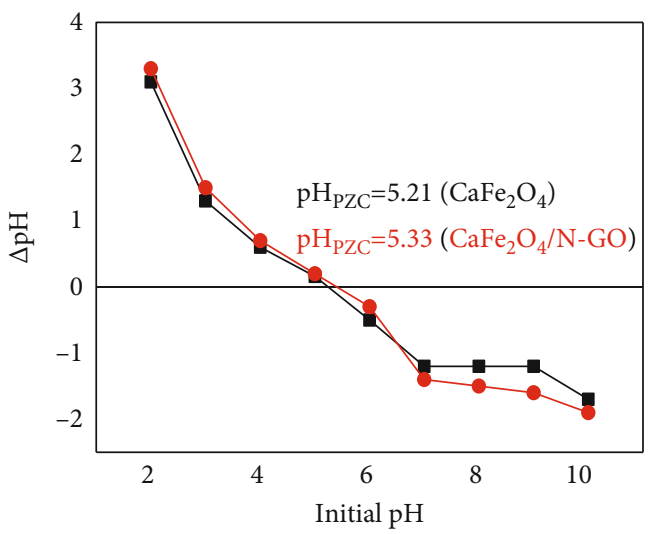

(c)

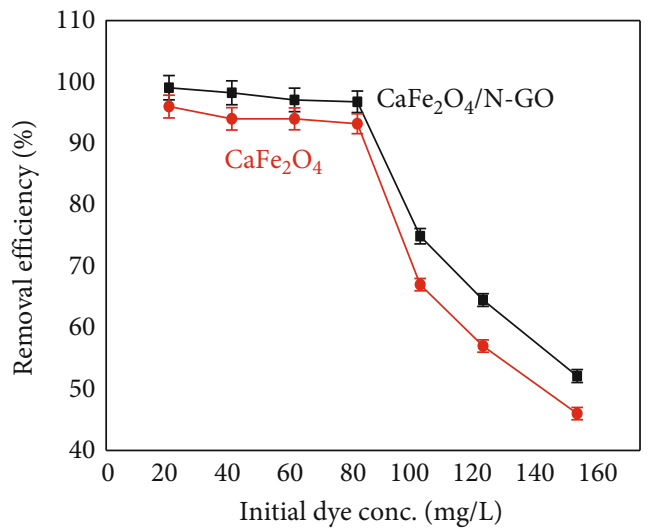

(e)

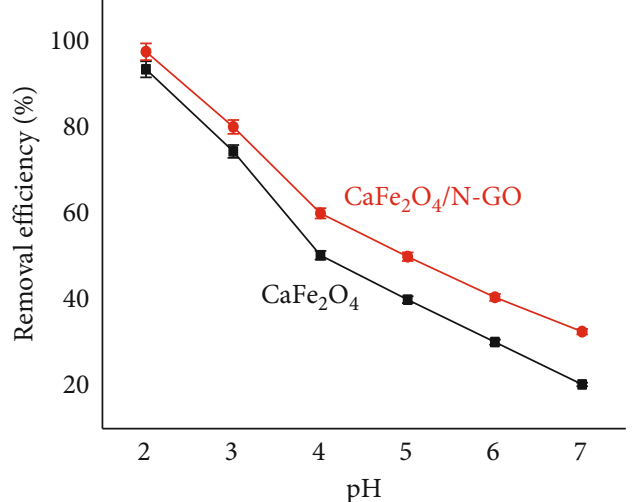

(b)

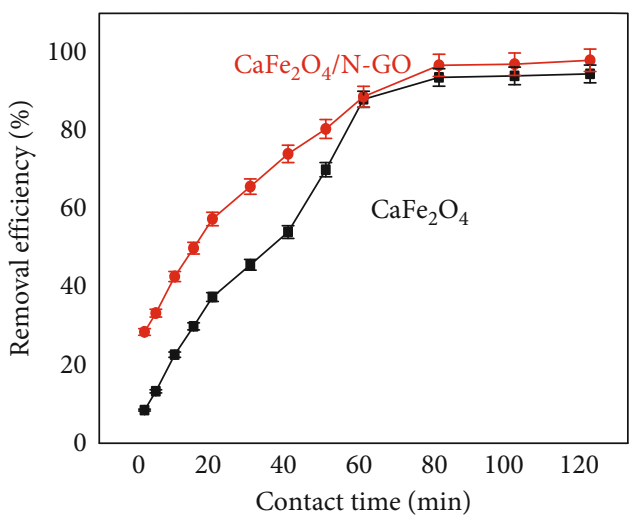

(d)

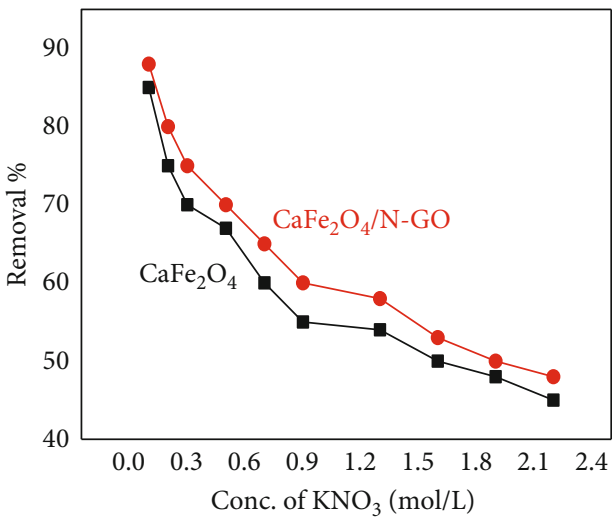

(f)

FIgURe 6: The effect of adsorbent dose (a), effect of $\mathrm{pH}(\mathrm{b})$, point of zero charge (c), effect of contact time (d), effect of initial dye concentration (e), and effect of ionic strength (f) for the removal of $\mathrm{RO} 12$ dye over $\mathrm{CaFe}_{2} \mathrm{O}_{4}$ nanoparticles and CaFe $\mathrm{O}_{4} / \mathrm{N}-\mathrm{GO}$ nanocomposite.

temperature. For the $\mathrm{CaFe}_{2} \mathrm{O}_{4} / \mathrm{N}-\mathrm{GO}$ nanocomposite TGA curve, it is clear that the introduction of $\mathrm{CaFe}_{2} \mathrm{O}_{4}$ nanoparticles to the carbon skeleton of $\mathrm{N}-\mathrm{GO}$ caused improvement to the thermal properties. This may be attributed to increased loadings of $\mathrm{CaFe}_{2} \mathrm{O}_{4}$ nanoparticles predictably decreasing the carbon content within the $\mathrm{CaFe}_{2} \mathrm{O}_{4} / \mathrm{N}-\mathrm{GO}$ nanocomposite. The TGA data indicates the excellent thermal properties of the synthesized nanocomposite and confirms the well construction of the nanocomposite. Moreover, the $\mathrm{N}_{2}$ adsorption-desorption isotherm was performed for $\mathrm{CaFe}_{2} \mathrm{O}_{4}$ nanoparticles and $\mathrm{CaFe}_{2} \mathrm{O}_{4} / \mathrm{N}-\mathrm{GO}$ nanocomposite to determine their surface properties as shown in Figure 5. According to Figure 5, the synthesized materials have mesoporous structure as they have type IV isotherm of $\mathrm{H} 3$ type hysteresis loop. The $\mathrm{CaFe}_{2} \mathrm{O}_{4}$ nanoparticles showed BET surface area of $24.0 \mathrm{~m}^{2} \mathrm{~g}^{-1}$. After the addition of N-GO nanosheets, this area was increased to $52.93 \mathrm{~m}^{2} \mathrm{~g}^{-1}$. The addition of nanosheets caused the well distribution of magnetic nanoparticles and prevented their agglomeration by magnetic attraction. This well distribution of nanoparticles was the reason for 
higher $\mathrm{CaFe}_{2} \mathrm{O}_{4} / \mathrm{N}-\mathrm{GO}$ nanocomposite' BET surface area than $\mathrm{CaFe}_{2} \mathrm{O}_{4}$ nanoparticles. Also, the higher surface area of $\mathrm{CaFe}_{2} \mathrm{O}_{4} / \mathrm{N}-\mathrm{GO}$ nanocomposite suggested the higher mesoporosity than $\mathrm{CaFe}_{2} \mathrm{O}_{4}$ nanoparticles. The determined surface area, pore volume, and pore diameter of synthesized materials using BET study were introduced in Table 1. $\mathrm{CaFe}_{2} \mathrm{O}_{4} / \mathrm{N}-\mathrm{GO}$ nanocomposite showed a higher pore volume than $\mathrm{CaFe}_{2} \mathrm{O}_{4}$ nanoparticles that reflected the higher surface area of the nanocomposite. Also, the higher surface area of the nanocomposite was indicated from the micropore volume values. This large micropore volume and BET surface area play a significant role in the removal of pollutants from aqueous solution as described in the literature $[9,10,46]$.

\subsection{Dye Removal}

3.2.1. Optimization of the Adsorption Conditions. The adsorption process is controlled by several parameters such as initial concentration of dye, contact time, adsorbent dosage, and $\mathrm{pH}$, which are the basis of all laboratory experiments laboratories aiming to determine optimum conditions to get the highest efficiency of the adsorbent. Subsequently, the next section includes the study of the effect of different parameters on RO12 removal on the surface of the synthesized nanomaterials. To study the effect of the adsorbent dosage on RO12 removal, different dosages ranging from 0.125 to $1 \mathrm{~g} / \mathrm{L}$ were investigated for the removal of RO12 dye as shown in Figure 6(a). According to Figure 5(a), the removal efficiency of RO12 dye was increased from $25.0 \% \pm 0.5$ to $93.26 \% \pm 0.38$ and from $40.56 \% \pm 0.42$ to $96.77 \% \pm 0.63$ for $\mathrm{CaFe}_{2} \mathrm{O}_{4}$ nanoparticles and $\mathrm{CaFe}_{2} \mathrm{O}_{4} / \mathrm{N}-\mathrm{GO}$ nanocomposite, respectively, when the dosage increased from 0.125 to $1 \mathrm{~g} / \mathrm{L}$. This increase of removal efficiency associated with the increase of adsorbent dosage is attributed to the presence of more available adsorption sites by increasing the dosage. While at adsorbent dosage higher than $1 \mathrm{~g} / \mathrm{L}$, there was no significance increase of $\mathrm{RO} 12$ removal efficiency on the surface of $\mathrm{CaFe}_{2} \mathrm{O}_{4}$ nanoparticles or $\mathrm{CaFe}_{2} \mathrm{O}_{4} / \mathrm{N}-\mathrm{GO}$ nanocomposite, which is attributed to the achievement of the saturation state and the agglomeration of the adsorbent particles and the blockage of adsorption sites [47]. The removal efficiency of dye on the surface of $\mathrm{CaFe}_{2} \mathrm{O}_{4} / \mathrm{N}-\mathrm{GO}$ nanocomposite was higher than on the surface of $\mathrm{CaFe}_{2} \mathrm{O}_{4}$ nanoparticles due to the presence of $\mathrm{N}-\mathrm{GO}$ nanosheets providing more active sites and $\mathrm{N}$-atoms for the chelation of dye molecules.

The effect of $\mathrm{pH}$ on the removal of $\mathrm{RO} 12$ dye using $\mathrm{CaFe}_{2} \mathrm{O}_{4}$ nanoparticles and $\mathrm{CaFe}_{2} \mathrm{O}_{4} / \mathrm{N}-\mathrm{GO}$ nanocomposite was studied by varying the initial $\mathrm{pH}$ within the range of 2.0 to 7.0 as shown in Figure 6(b). According to Figure 6(b), the $\mathrm{pH}$ increase caused a decrease in the removal efficiency of RO12 until reaching the lowest value at $\mathrm{pH}$ of 7.0 , which is equal to $20.28 \% \pm 0.36$ and $32.56 \%$ \pm 0.54 for $\mathrm{CaFe}_{2} \mathrm{O}_{4}$ nanoparticles and $\mathrm{CaFe}_{2} \mathrm{O}_{4} / \mathrm{N}-\mathrm{GO}$ nanocomposite, respectively. The highest removal efficiency was achieved at a $\mathrm{pH}$ of 2.0 , which is considered the optimum $\mathrm{pH}$ value for dye removal. This behavior could be interpreted as at low $\mathrm{pH}$ value, and the adsorbent surface
TABLE 2: The kinetics and isotherm parameters for the removal of RO12 dye on the surface of $\mathrm{CaFe}_{2} \mathrm{O}_{4}$ nanoparticles and $\mathrm{CaFe}_{2} \mathrm{O}_{4} /$ $\mathrm{N}-\mathrm{GO}$ nanocomposite.

\begin{tabular}{|c|c|c|c|}
\hline \multirow[b]{2}{*}{ Item } & \multirow[b]{2}{*}{ Coefficient } & \multicolumn{2}{|c|}{ Adsorbent } \\
\hline & & $\mathrm{CaFe}_{2} \mathrm{O}_{4}$ & $\begin{array}{c}\mathrm{CaFe}_{2} \mathrm{O}_{4} / \mathrm{N}- \\
\mathrm{GO}\end{array}$ \\
\hline \multirow{3}{*}{ Pseudo $1^{\text {st }}$ order } & $R^{2}$ & 0.916 & 0.949 \\
\hline & $k_{1}(\mathrm{~L} / \mathrm{min})$ & 4.551 & 3.611 \\
\hline & $q_{e}(\mathrm{mg} / \mathrm{g})$ & 181.0 & 132.0 \\
\hline \multirow{3}{*}{ Pseudo $2^{\text {nd }}$ order } & $R^{2}$ & 0.996 & 0.998 \\
\hline & $K_{2}$ (g/mg.min) & 4.066 & 4.994 \\
\hline & $q_{e}(\mathrm{mg} / \mathrm{g})$ & 256.0 & 287.0 \\
\hline \multirow{3}{*}{$\begin{array}{l}\text { Intraparticle } \\
\text { diffusion }\end{array}$} & $R^{2}$ & 0.770 & 0.824 \\
\hline & $C^{\text {id }}$ & 120.20 & 168.57 \\
\hline & $K^{\text {id }}$ & 11.279 & 9.835 \\
\hline \multirow{3}{*}{ Freundlich isotherm } & $R^{2}$ & 0.952 & 0.951 \\
\hline & $1 / n$ & 0.4539 & 0.3934 \\
\hline & $K_{F}(\mathrm{~L} \cdot \mathrm{mg} / \mathrm{g})$ & 33.0 & 61.0 \\
\hline \multirow{3}{*}{ Langmuir isotherm } & $R^{2}$ & 0.960 & 0.980 \\
\hline & $B(\mathrm{~L} / \mathrm{mg})$ & 0.074 & 0.189 \\
\hline & $q_{\max }(\mathrm{mg} / \mathrm{g})$ & 250.0 & 333.33 \\
\hline
\end{tabular}

was protonated to form positively charged functional groups that act as chelation sites to uptake the anionic RO12 dye via electrostatic interaction. While at higher $\mathrm{pH}$ values, the functional groups of adsorbent become negatively charged and repulsed with the anionic dye causing the decrease in the removal efficiency. Moreover, at high $\mathrm{pH}$ value, the presence of $\mathrm{OH}^{-}$groups could compete with the anionic dye for the active sites on the adsorbent surface which affect the removal efficiency negatively $[48,49]$. As reported in the literature, $\mathrm{pH}$ affects the degree of ionization of the adsorptive molecules, the surface charge, and the dissociation degree of the functional groups of the adsorbent active site [50-52]. Therefore, the results of $\mathrm{pH}$ effect indicated that the $\mathrm{pH}$ is a key factor for dye adsorption. Moreover, the determination of point of zero charge $\left(\mathrm{pH}_{\mathrm{PZC}}\right)$ for $\mathrm{CaFe}_{2} \mathrm{O}_{4}$ nanoparticles and $\mathrm{CaFe}_{2} \mathrm{O}_{4} / \mathrm{N}-\mathrm{GO}$ nanocomposite is important to determine the $\mathrm{pH}$ effect on the adsorption process. Subsequently, the $\mathrm{pH}_{\mathrm{PZC}}$ was determined for $\mathrm{CaFe}_{2} \mathrm{O}_{4}$ nanoparticles and $\mathrm{CaFe}_{2} \mathrm{O}_{4} / \mathrm{N}-\mathrm{GO}$ nanocomposite as shown in Figure 6(c). The $\mathrm{pH}_{\text {PZC }}$ values were found to equal 5.21 and 5.33 for $\mathrm{CaFe}_{2} \mathrm{O}_{4}$ nanoparticles and $\mathrm{CaFe}_{2} \mathrm{O}_{4} / \mathrm{N}-\mathrm{GO}$ nanocomposite, respectively. This means that below the $\mathrm{pH}_{\mathrm{PZC}}$, the adsorbent is positively charged while above the $\mathrm{pH}_{\mathrm{PZC}}$, and the adsorbent is negatively charged. The $\mathrm{pH}_{\mathrm{PZC}}$ determination interprets the high removal efficiency of RO12 dye at low $\mathrm{pH}$ values. At low $\mathrm{pH}$ value $<\mathrm{pH}_{\mathrm{PZC}}$, the adsorbent surface was positively charged and attracted the anionic dye via the electrostatic attractions. While at higher $\mathrm{pH}$ value $>\mathrm{pH}_{\mathrm{PZC}}$, the adsorbent surface was negatively charged and repulsed the anionic dye. So, the determination of $\mathrm{pH}_{\mathrm{PZC}}$ values enhances the results of $\mathrm{pH}$ effect on the adsorption process. 


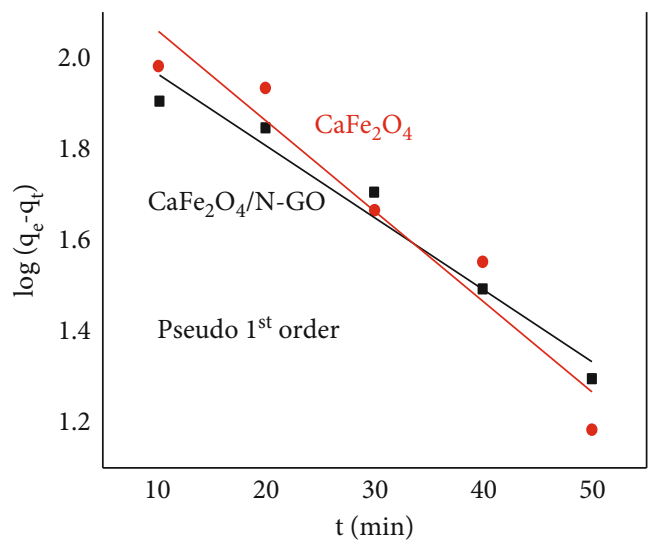

(a)

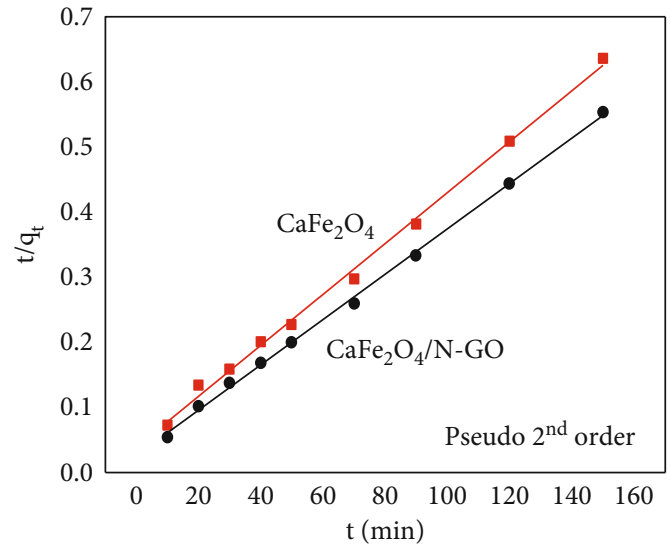

(b)

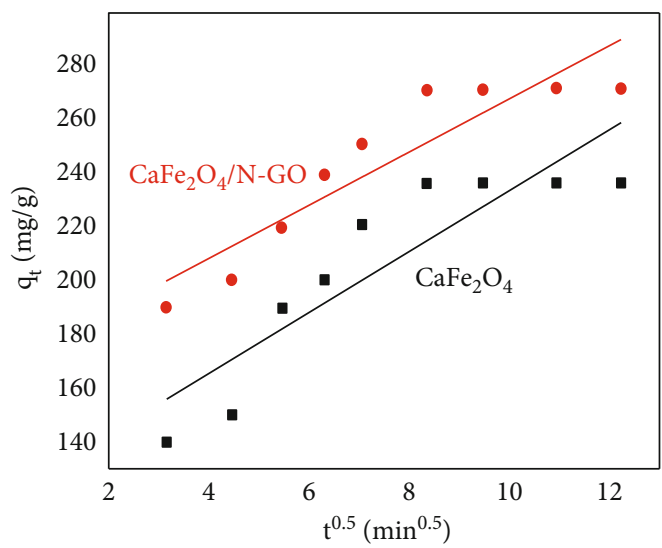

(c)

FIGURE 7: Fitting the experimental data to pseudo $1^{\text {st }}$ order kinetics (a), pseudo $2^{\text {nd }}$ order kinetics (b), and intraparticle diffusion model (c) for the adsorption of $\mathrm{RO} 12$ dye on the surface of $\mathrm{CaFe}_{2} \mathrm{O}_{4}$ nanoparticles and $\mathrm{CaFe}_{2} \mathrm{O}_{4} / \mathrm{N}-\mathrm{GO}$ nanocomposite.

The effect of the contact time on dye removal by $\mathrm{CaFe}_{2} \mathrm{O}_{4}$ nanoparticles and $\mathrm{CaFe}_{2} \mathrm{O}_{4} / \mathrm{N}-\mathrm{GO}$ nanocomposite was studied at different intervals ranging from 10.0 to 120 minutes as shown in Figure 6(d). According to Figure 6(c), the dye removal rate increased with an increase in contact time. At the beginning, a rapid removal was observed, which is attributed to the availability of protonated adsorbent sites to interact with anionic dye through the electrostatic interaction. Then, there was a decrease in the removal rate until reached the equilibrium that is attributed to the reduced surface area of the adsorbent due to the adsorbed dye, and also the adsorbed molecules are repulsed with each other [53]. The optimum contact time for the adsorption of RO12 dye on the surface of $\mathrm{CaFe}_{2} \mathrm{O}_{4}$ nanoparticles and $\mathrm{CaFe}_{2} \mathrm{O}_{4} / \mathrm{N}$ GO nanocomposite was 80.0 minutes at which the equilibrium was reached as clearly shown in Figure 6(d). To study the effect of the initial dye concentration on the removal of $\mathrm{RO} 12$ using $\mathrm{CaFe}_{2} \mathrm{O}_{4}$ nanoparticles and $\mathrm{CaFe}_{2} \mathrm{O}_{4} / \mathrm{N}-\mathrm{GO}$ nanocomposite, the initial concentration was varied from 20 to $150 \mathrm{mg} / \mathrm{L}$ as shown in Figure 6(e). According to Figure 6(e), the removal efficiency of dye was decreased by increasing the dye concentration gradually until $80 \mathrm{mg} / \mathrm{L}$, at which there was a drop in the removal efficiency. This behavior was attributed to the increased amount of dye mol- ecules against the fixed number of adsorption sites, causing the drop in the removal efficiency. However, at low dye concentration, several free adsorption sites are available to uptake the dye. To study the effect of ionic strength on the removal of RO12 dye on the surface of $\mathrm{CaFe}_{2} \mathrm{O}_{4}$ nanoparticles and $\mathrm{CaFe}_{2} \mathrm{O}_{4} / \mathrm{N}-\mathrm{GO}$ nanocomposite, the removal efficiency was determined at different concentrations of $\mathrm{KNO}_{3}$ salt as shown in Figure 6(f). According to Figure 6(f), the removal efficiency was decreased by increasing the ionic strength until reaching $45 \%$ and $48 \%$ for $\mathrm{CaFe}_{2} \mathrm{O}_{4}$ nanoparticles and $\mathrm{CaFe}_{2} \mathrm{O}_{4} / \mathrm{N}-\mathrm{GO}$ nanocomposite, respectively, at ionic strength of $2.2 \mathrm{~mol} \cdot \mathrm{L}^{-1}$. This behavior was expected in the presence of $\mathrm{KNO}_{3}$ that supports the ion exchange mechanism of the adsorption process [51]. This means that the counterions around the adsorption sites weaken the attraction forces between adsorbent and adsorbate and cause a decrease in the removal efficiency [51].

3.2.2. Adsorption Kinetics and Isotherm. The adsorption process is perfectly imaged through the study of the adsorption rate $[54,55]$. The adsorption rate is an important parameter that can be described using different kinetic models such as pseudo $1^{\text {st }}$ order model and pseudo $2^{\text {nd }}$ order model. Subsequently, the experimental data for the removal of RO12 dye 


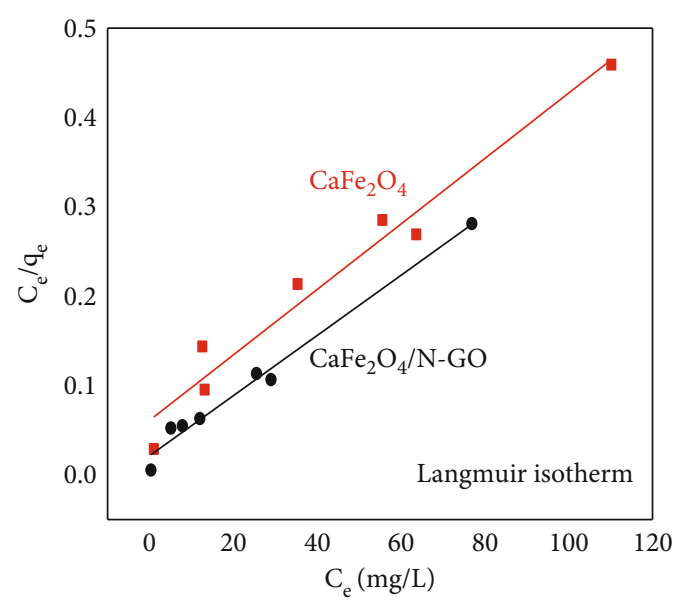

(a)

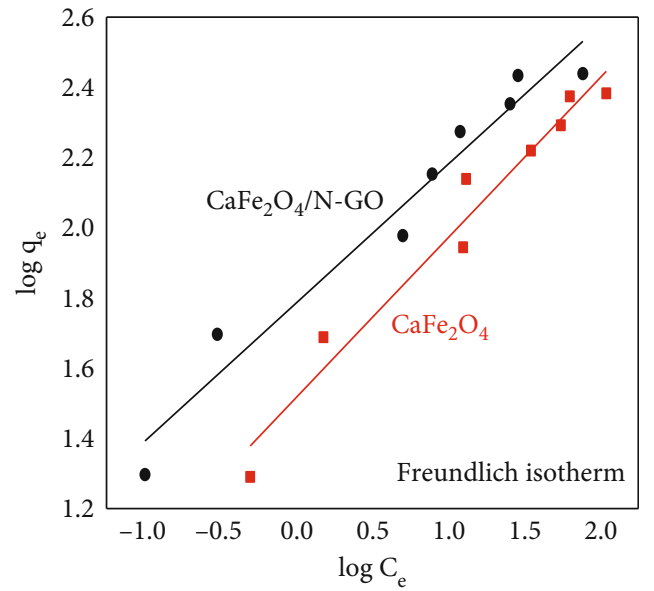

(b)

FIgURE 8: Fitting the experimental data to Langmuir isotherm model (a) and Freundlich isotherm model (b) for the adsorption of RO12 dye on the surface of $\mathrm{CaFe}_{2} \mathrm{O}_{4}$ nanoparticles and $\mathrm{CaFe}_{2} \mathrm{O}_{4} / \mathrm{N}-\mathrm{GO}$ nanocomposite.

using $\mathrm{CaFe}_{2} \mathrm{O}_{4}$ nanoparticles and $\mathrm{CaFe}_{2} \mathrm{O}_{4} / \mathrm{N}-\mathrm{GO}$ nanocomposite was fitted using the pseudo $1^{\text {st }}$ order model and pseudo $2^{\text {nd }}$ order model as shown in Figure 6. The kinetic parameters were calculated and presented in Table 2. From the results in Table 2 , the $R^{2}$ values showed that pseudo $2^{\text {nd }}$ order model is higher fitting the experimental data than pseudo $1^{\text {st }}$ order model in case of $\mathrm{CaFe}_{2} \mathrm{O}_{4}$ nanoparticles and $\mathrm{CaFe}_{2} \mathrm{O}_{4} / \mathrm{N}-\mathrm{GO}$ nanocomposite. Additionally, the experimental values of $q_{e}$ indicated the agreement with pseudo $2^{\text {nd }}$ order. Also, Figure 7 indicates the excellent agreement with pseudo $2^{\text {nd }}$ order model to the experimental adsorption data. This agreement of adsorption data with the pseudo $2^{\text {nd }}$ order model indicates that the removal of RO12 dye achieved through the chemisorption between the dye and $\mathrm{CaFe}_{2} \mathrm{O}_{4}$ nanoparticles and $\mathrm{CaFe}_{2} \mathrm{O}_{4} / \mathrm{N}-\mathrm{GO}$ nanocomposite $[56,57]$.

This kinetic behavior is similar to many previously reported studies for the removal of RO12 dye [37, 58]. To get an idea about the diffusion mechanism, the Webber's pore-diffusion model (intraparticle diffusion model) was used as shown in Figure 7(c). According to Figure 7(c), the plot of intraparticle diffusion model between $t^{0.5}$ and $q_{t}$ showed the existence of three different stages suggesting three different mechanisms of adsorption. The $1^{\text {st }}$ stage represents the diffusion of $\mathrm{RO} 12$ dye on the surface of adsorbents $\left(\mathrm{CaFe}_{2} \mathrm{O}_{4}\right.$ and $\left.\mathrm{CaFe}_{2} \mathrm{O}_{4} / \mathrm{N}-\mathrm{GO}\right)$ from the bulk solution, the $2^{\text {nd }}$ stage represents the pore diffusion, and the $3^{\text {rd }}$ stage represents the achievement of equilibrium state $[18,59]$.

More insights about the adsorption process can be obtained from the study of the adsorption isotherm as the isotherm can describe the distribution of toxic ions at an equilibrium state between the solid-liquid phases [60]. Also, the isotherm study can be used for the determination of adsorption capacity as well as understanding the affinities between adsorbent and adsorbate ions. Therefore, in this study, the adsorption behavior was described using the adsorption isotherm models including Langmuir model and Freundlich model. Langmuir model suggests that the

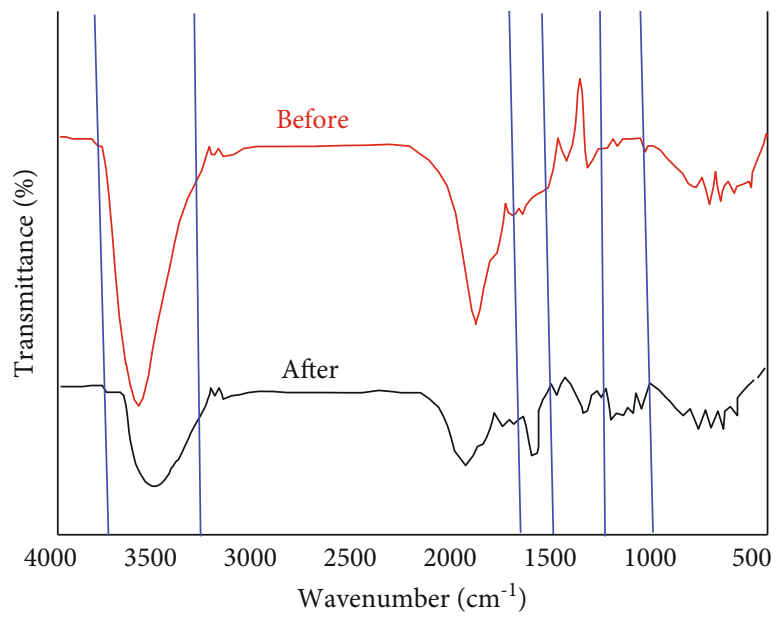

FIGURE 9: FT-IR spectra of $\mathrm{CaFe}_{2} \mathrm{O}_{4} / \mathrm{N}-\mathrm{GO}$ nanocomposite before and after the adsorption of RO12 dye.

adsorbate molecules not interacted with each other and result a monolayer adsorption of the adsorbate on the homogeneous surface of adsorbent [61]. While the Langmuir model suggests multilayer adsorption process resulted from the adsorption of adsorbate molecules on the heterogeneous surface of adsorbent [62]. The linear plots of Langmuir and Freundlich isotherm models are shown in Figure 8 , and the calculated parameters are presented in Table 2. According to the results in Table $1, R^{2}$ values showed a higher agreement of the experimental data with Langmuir model than Freundlich model in the case of $\mathrm{CaFe}_{2} \mathrm{O}_{4}$ nanoparticles and $\mathrm{CaFe}_{2} \mathrm{O}_{4} / \mathrm{N}-\mathrm{GO}$ nanocomposite. This indicated that the uptake of RO12 dye on the surface of $\mathrm{CaFe}_{2} \mathrm{O}_{4}$ nanoparticles and $\mathrm{CaFe}_{2} \mathrm{O}_{4} / \mathrm{N}-\mathrm{GO}$ nanocomposite was reached as a monolayer attachment between the dye molecules and the uniformly dispersed active sites on the surface of adsorbents. The monolayer adsorption is indicated that the adsorption process is greatly dependent on the properties of the surface. 
TABLE 3: Comparison between the removal of $\mathrm{RO} 12$ over $\mathrm{CaFe}_{2} \mathrm{O}_{4} / \mathrm{N}-\mathrm{GO}$ nanocomposite with previously reported adsorbents.

\begin{tabular}{lcc}
\hline Adsorbent & $q_{m}(\mathrm{mg} / \mathrm{g})$ & Ref. \\
\hline $\mathrm{CaFe}_{2} \mathrm{O}_{4} / \mathrm{N}-\mathrm{GO}$ & 333.33 & This study \\
$\mathrm{CaFe}_{2} \mathrm{O}_{4}$ & 250 & This study \\
$\mathrm{CaFe}_{2} \mathrm{O}_{4}$ & 276.92 & {$[34]$} \\
Platinum nanoparticles loaded on activated carbon & 285.143 & {$[35]$} \\
Copper sulfide nanoparticles loaded on activated carbon & 96.9 & {$[36]$} \\
Mn nanoparticles loaded on activated carbon & 94.52 & {$[37]$} \\
Cadmium sulfide nanoparticle-loaded activated carbon & 150.0 & {$[38]$} \\
Tin sulfide nanoparticle loaded on activated carbon & 157.73 & {$[39]$} \\
\hline
\end{tabular}

According to Langmuir fitting results, the maximum adsorption capacities $\left(q_{m}\right)$ are $250 \mathrm{mg} / \mathrm{g}$ and $333.33 \mathrm{mg} / \mathrm{g}$ for $\mathrm{CaFe}_{2} \mathrm{O}_{4}$ nanoparticles and $\mathrm{CaFe}_{2} \mathrm{O}_{4} / \mathrm{N}-\mathrm{GO}$ nanocomposite, respectively. The enhancement of the adsorption capacity of $\mathrm{CaFe}_{2} \mathrm{O}_{4} / \mathrm{N}-\mathrm{GO}$ nanocomposite can be attributed to the increased active sites associated with the addition of $\mathrm{N}-\mathrm{GO}$ sheets to the magnetic $\mathrm{CaFe}_{2} \mathrm{O}_{4}$ nanoparticles. As a result, $\mathrm{N}-\mathrm{GO}$ sheets provide more quantities of functional groups to the adsorbent causing an increase in the capacity of the adsorbent. Moreover, the N-GO sheets provide 3-D porous skeleton that can uptake the adsorbate molecules inside and, hence, increase the adsorption capacity. Additionally, the doping of $\mathrm{N}$ atoms in GO provides the amine groups allowing the enhancement of the pollutants uptake via hydrogen bonding and electrostatic interaction. All these factors play a significant role in the enhanced adsorption process of $\mathrm{RO} 12$ dye on the surface of $\mathrm{CaFe}_{2} \mathrm{O}_{4} / \mathrm{N}-\mathrm{GO}$ nanocomposite.

To get an insight about the removal mechanism of RO12 dye on the surface of $\mathrm{CaFe}_{2} \mathrm{O}_{4} / \mathrm{N}-\mathrm{GO}$ nanocomposite, the FT-IR spectra of the nanocomposite were studied before and after the dye adsorption as shown in Figure 9. According to Figure 9, the FT-IR spectrum of $\mathrm{CaFe}_{2} \mathrm{O}_{4} / \mathrm{N}-\mathrm{GO}$ nanocomposite showed many differences after the adsorption of RO12 dye. The band at $3435 \mathrm{~cm}^{-1}$ that correspond to $\mathrm{OH}$ group stretching vibrations was shifted, and its intensity was decreased indicating the contribution of $\mathrm{OH}$ groups in the removal mechanism. Similarly, the bands of other functional groups were shifted as a result of their contribution in the dye removal. Also, the appearance of the new bands at $1550 \mathrm{~cm}^{-1}$ and $1210 \mathrm{~cm}^{-1}$ was attributed to the azo-bond $(\mathrm{N}=\mathrm{N})$ vibrations, and sulfonate group of the dye, respectively, indicated the successful adsorption of the dye on the surface of nanocomposite.

To highlight the effectiveness of the synthesized $\mathrm{CaFe}_{2} \mathrm{O}_{4} / \mathrm{N}-\mathrm{GO}$ nanocomposite as an RO 12 adsorbent, the maximum adsorption capacity obtained here for RO 12 was compared with previously reported results (Table 3 ). According to previously reported results, $\mathrm{CaFe}_{2} \mathrm{O}_{4} / \mathrm{N}-\mathrm{GO}$ nanocomposite revealed excellent adsorption capacity for RO12 compared to the reported adsorbents. Therefore, it could be concluded that the designed magnetic $\mathrm{CaFe}_{2} \mathrm{O}_{4} /$ $\mathrm{N}-\mathrm{GO}$ nanocomposite will be a promising hopeful hybrid nanomaterial useful as adsorbent for the elimination of dyes from wastewater.

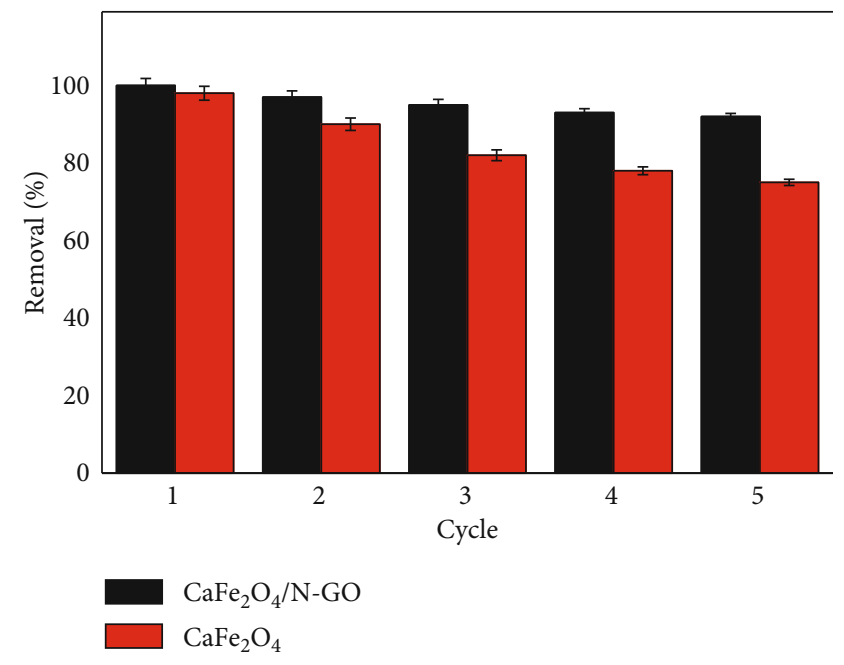

FIgURE 10: Reusability study of the synthesized $\mathrm{CaFe}_{2} \mathrm{O}_{4}$ nanoparticles and $\mathrm{CaFe}_{2} \mathrm{O}_{4} / \mathrm{N}-\mathrm{GO}$ nanocomposite for the removal of RO12 dye up to five cycles.

3.3. Reusability Study. The important advantage of any adsorbent is its reusability which could reduce the process cost and enhance its application at large-scale [63-65]. The reusability of the synthesized $\mathrm{CaFe}_{2} \mathrm{O}_{4}$ nanoparticles and $\mathrm{CaFe}_{2} \mathrm{O}_{4} / \mathrm{N}-\mathrm{GO}$ nanocomposites was determined by repeating the adsorption-desorption cycles up to 5 cycles. The adsorbents were allowed to adsorb the RO12 dye. Then, the adsorbents were collected using an external magnet, and the solution was examined for the presence of dye. The adsorbed dye molecules were desorbed by immersing the adsorbents in $0.1 \mathrm{M} \mathrm{NaOH}$ for half-hour. After that, the adsorbents were washed using $0.1 \mathrm{M} \mathrm{HCl}$ to be used in the next cycle. The reusability results for the removal of $\mathrm{RO} 12$ dye using $\mathrm{CaFe}_{2} \mathrm{O}_{4}$ nanoparticles and $\mathrm{CaFe}_{2} \mathrm{O}_{4} / \mathrm{N}$ $\mathrm{GO}$ nanocomposite are shown in Figure 10. The removal efficiency of $\mathrm{CaFe}_{2} \mathrm{O}_{4}$ nanoparticles and $\mathrm{CaFe}_{2} \mathrm{O}_{4} / \mathrm{N}-\mathrm{GO}$ nanocomposites remained above $80 \% \pm 1$ (after $3^{\text {rd }}$ cycle) and $90 \% \pm 1$ (after $5^{\text {th }}$ cycle), respectively.

Subsequently, both synthesized adsorbents are excellent choices for water treatment. But, the $\mathrm{CaFe}_{2} \mathrm{O}_{4} / \mathrm{N}-\mathrm{GO}$ nanocomposite is better than $\mathrm{CaFe}_{2} \mathrm{O}_{4}$ nanoparticles and more efficient due to the higher adsorption capacity and higher reusability results. All results indicated that the $\mathrm{CaFe}_{2} \mathrm{O}_{4} /$ $\mathrm{N}-\mathrm{GO}$ nanocomposite is a promising nanosorbent for the 
water treatment and must be examined for the removal of additional pollutants in the future.

\section{Conclusion}

The facile ultrasonication method was used for the successful synthesis of magnetic $\mathrm{CaFe}_{2} \mathrm{O}_{4} / \mathrm{N}-\mathrm{GO}$ nanocomposite. The synthesized materials were characterized using different methods including FT-IR, XRD, SEM, TEM, magnetization curve, and $\mathrm{N}_{2}$ adsorption-desorption isotherm. The synthesized magnetic $\mathrm{CaFe}_{2} \mathrm{O}_{4} / \mathrm{N}-\mathrm{GO}$ nanocomposite was examined for the adsorption of RO12 dye and compared with $\mathrm{CaFe}_{2} \mathrm{O}_{4}$ nanoparticles. In order to optimize the adsorption process, the effects of different factors including the initial dye concentration, $\mathrm{pH}$, contact time, and adsorbent dose on the adsorption process were studied. The adsorption kinetics that was studied indicated that the pseudo $2^{\text {nd }}$ order model was the best for the description of RO12 uptake on the surface of $\mathrm{CaFe}_{2} \mathrm{O}_{4} / \mathrm{N}-\mathrm{GO}$ nanocomposite and $\mathrm{CaFe}_{2} \mathrm{O}_{4}$ nanoparticles. Langmuir and Freundlich isotherm models were used to study the adsorption isotherm, and the best fitting was achieved using Langmuir isotherm model. The addition of $\mathrm{N}-\mathrm{GO}$ to $\mathrm{CaFe}_{2} \mathrm{O}_{4}$ nanoparticles during the nanofabrication of the nanocomposite enhanced the $\mathrm{RO} 12$ removal efficiency. The maximum adsorption capacity $\left(q_{m}\right)$ of $\mathrm{CaFe}_{2} \mathrm{O}_{4} / \mathrm{N}-\mathrm{GO}$ nanocomposite for $\mathrm{RO} 12$ dye was $333.33 \mathrm{mg} / \mathrm{g}$ which was greater than that of $\mathrm{CaFe}_{2} \mathrm{O}_{4}$ nanoparticles $(250 \mathrm{mg} / \mathrm{g})$. The higher adsorption capacity of $\mathrm{CaFe}_{2} \mathrm{O}_{4} / \mathrm{N}-\mathrm{GO}$ nanocomposite was related to the addition of N-GO which increased the nanosorbent surface area and provided the nitrogen centers for capturing more toxic molecules. Interestingly, $\mathrm{CaFe}_{2} \mathrm{O}_{4} / \mathrm{N}-\mathrm{GO}$ nanocomposite showed excellent adsorption capacity for RO12 compared to other adsorbents reported in the literature. Moreover, the reusability of the synthesized nanomaterials was studied up to 5 cycles with excellent results. Finally, it could be concluded that the nanofabricated $\mathrm{CaFe}_{2} \mathrm{O}_{4} / \mathrm{N}-\mathrm{GO}$ will be a cost-effective and promising adsorbent for the elimination of RO12 from wastewater.

\section{Data Availability}

The research data used to support the findings of this study are included within the article.

\section{Conflicts of Interest}

The authors declare that they have no conflicts of interest.

\section{Acknowledgments}

The authors extend their appreciation to the Deanship of Scientific Research at King Khalid University for funding this work through the research groups program under grant number RGP.2/157/42. Additionally, Princess Nourah bint Abdulrahman University Researchers Supporting Project number (PNURSP2022R19), Princess Nourah bint Abdulrahman University, Riyadh, Saudi Arabia.

\section{References}

[1] S. M. Siddeeg, M. A. Tahoon, N. S. Alsaiari, M. Shabbir, and F. B. Rebah, "Application of functionalized nanomaterials as effective adsorbents for the removal of heavy metals from wastewater: a review," Current Analytical Chemistry, vol. 17, pp. 4-22, 2021.

[2] L. Zhou, C. Gao, and W. Xu, "Magnetic dendritic materials for highly efficient adsorption of dyes and drugs," ACS Applied Materials \& Interfaces, vol. 2, no. 5, pp. 1483-1491, 2010.

[3] Q. Xu, D. Sun, Y. Qi, and L. Duan, "Efficient removal of anionic organic dyes from aqueous solution with cu-organic frameworks," Chemical Engineering \& Technology, vol. 42, no. 5, pp. 1070-1077, 2019.

[4] N. K. Nga, P. T. T. Hong, T. Dai Lam, and T. Q. Huy, "A facile synthesis of nanostructured magnesium oxide particles for enhanced adsorption performance in reactive blue 19 removal," Journal of Colloid and Interface Science, vol. 398, pp. 210-216, 2013.

[5] M. Bhowmik, K. Deb, A. Debnath, and B. Saha, "Mixed phase $\mathrm{Fe} 2 \mathrm{O} 3 / \mathrm{Mn} 3 \mathrm{O} 4$ magnetic nanocomposite for enhanced adsorption of methyl orange dye: neural network modeling and response surface methodology optimization," Applied Organometallic Chemistry, vol. 32, no. 3, article e4186, 2018.

[6] S. Hwang, M. Choi, J. Lee et al., "Infiltrated thin film structure with hydrogel-mediated precursor ink for durable SOFCs," Scientific Reports, vol. 11, no. 1, p. 7109, 2021.

[7] K. Sathishkumar, M. S. AlSalhi, E. Sanganyado, S. Devanesan, A. Arulprakash, and A. Rajasekar, "Sequential electrochemical oxidation and bio-treatment of the azo dye Congo red and textile effluent," Journal of Photochemistry and Photobiology B: Biology, vol. 200, article 111655, 2019.

[8] P. Chanikya, P. V. Nidheesh, D. S. Babu, A. Gopinath, and M. S. Kumar, "Treatment of dyeing wastewater by combined sulfate radical based electrochemical advanced oxidation and electrocoagulation processes," Separation and Purification Technology, vol. 254, article 117570, 2021.

[9] S. Sugashini, T. Gomathi, R. A. Devi, P. N. Sudha, K. Rambabu, and F. Banat, "Nanochitosan/carboxymethyl cellulose/TiO biocomposite for visible-light-induced photocatalytic degradation of crystal violet dye," Environmental Research, vol. 204, article 112047, 2022.

[10] C. Yu, Z. Wu, R. Liu et al., "Novel fluorinated $\mathrm{Bi}_{2} \mathrm{MoO}_{6}$ nanocrystals for efficient photocatalytic removal of water organic pollutants under different light source illumination," Applied Catalysis B: Environmental, vol. 209, pp. 1-11, 2017.

[11] M. L. Christensen, K. Keiding, P. H. Nielsen, and M. K. Jørgensen, "Dewatering in biological wastewater treatment: a review," Water Research, vol. 82, pp. 14-24, 2015.

[12] Y. K. Ong, F. Y. Li, S.-P. Sun, B.-W. Zhao, C.-Z. Liang, and T.S. Chung, "Nanofiltration hollow fiber membranes for textile wastewater treatment: Lab- scale and pilot-scale studies," Chemical Engineering Science, vol. 114, pp. 51-57, 2014.

[13] G. R. Delpiano, D. Tocco, L. Medda, E. Magner, and A. Salis, "Adsorption of malachite green and alizarin red s dyes using fe-btc metal organic framework as adsorbent," International Journal of Molecular Sciences, vol. 22, no. 2, p. 788, 2021.

[14] B. Othmani, J. A. Gamelas, M. G. Rasteiro, and M. Khadhraoui, "Characterization of two cactus formulationbased flocculants and investigation on their flocculating ability for cationic and anionic dyes removal," Polymers, vol. 2020, p. 12, 1964. 
[15] X. Luo, C. Liang, and Y. Hu, "Comparison of different enhanced coagulation methods for azo dye removal from wastewater," Sustainability, vol. 11, p. 4760, 2019.

[16] F. Sharif and E. P. Roberts, "Electrochemical oxidation of an organic dye adsorbed on tin oxide and antimony doped tin oxide graphene composites," Catalysts, vol. 10, p. 263, 2020.

[17] K. M. Katubi, F. M. Alzahrani, N. S. Alsaiari, A. Amari, F. B. Rebah, and M. A. Tahoon, "Partially reduced graphene oxide modified with polyacrylonitrile for the removal of Sm3+ from water," Processes, vol. 9, no. 5, p. 818, 2021.

[18] R. N. Queiroz, P. Prediger, and M. G. A. Vieira, “Adsorption of polycyclic aromatic hydrocarbons from wastewater using graphene- based nanomaterials synthesized by conventional chemistry and green synthesis: A critical review," Journal of Hazardous Materials, vol. 422, article 126904, 2022.

[19] A. Alonso, J. Moral-Vico, A. A. Markeb et al., "Critical review of existing nanomaterial adsorbents to capture carbon dioxide and methane," Science of the Total Environment, vol. 595, pp. 51-62, 2017.

[20] K. B. Tan, M. Vakili, B. A. Horri, P. E. Poh, A. Z. Abdullah, and B. Salamatinia, "Adsorption of dyes by nanomaterials: recent developments and adsorption mechanisms," Separation and Purification Technology, vol. 150, pp. 229-242, 2015.

[21] W. Zhu, X. Jiang, K. Jiang, F. Liu, F. You, and C. Yao, "Fabrication of reusable carboxymethyl cellulose/graphene oxide composite aerogel with large surface area for adsorption of methylene blue," Nanomaterials, vol. 11, no. 6, p. 1609, 2021.

[22] P. de Luca, A. Chiodo, A. Macario, C. Siciliano, and B. J. Nagy, "Semi-continuous adsorption processes with multi-walled carbon nanotubes for the treatment of water contaminated by an organic textile dye," Applied Sciences, vol. 11, no. 4, p. 1687, 2021.

[23] S. Alam, M. S. Khan, W. Bibi et al., "Preparation of activated carbon from the wood of Paulownia tomentosa as an efficient adsorbent for the removal of acid red 4 and methylene blue present in wastewater," Water, vol. 13, p. 1453, 2021.

[24] F. Duan, Y. Yang, Y. Li, H. Cao, Y. Wang, and Y. Zhang, "Heterogeneous Fenton-like degradation of 4-chlorophenol using iron/ordered mesoporous carbon catalyst," Journal of Environmental Sciences, vol. 26, no. 5, pp. 1171-1179, 2014.

[25] A. Amari, N. Elboughdiri, D. Ghernaout et al., "Multifunctional crosslinked chitosan/nitrogen-doped graphene quantum dot for wastewater treatment," Ain Shams Engineering Journal, vol. 12, no. 4, pp. 4007-4014, 2021.

[26] T. Song, W. Tian, K. Qiao et al., "Adsorption behaviors of polycyclic aromatic hydrocarbons and oxygen derivatives in wastewater on N-doped reduced graphene oxide," Separation and Purification Technology, vol. 254, article 117565, 2021.

[27] N. S. Alsaiari, F. M. Alzahrani, K. M. Katubi, A. Amari, F. B. Rebah, and M. A. Tahoon, "Polyethylenimine-modified magnetic chitosan for the uptake of arsenic from water," Applied Sciences, vol. 11, p. 5630, 2021.

[28] S. M. Siddeeg, A. Amari, M. A. Tahoon, N. S. Alsaiari, and F. B. Rebah, "Removal of meloxicam, piroxicam and $\mathrm{Cd}^{+2}$ by $\mathrm{Fe}_{3} \mathrm{O}_{4} / \mathrm{SiO}_{2} /$ glycidyl methacrylate-S-SH nanocomposite loaded with laccase," Alexandria Engineering Journal, vol. 59, no. 2, pp. 905-914, 2020.

[29] F. M. Alzahrani, N. S. Alsaiari, K. M. Katubi, A. Amari, F. Ben Rebah, and M. A. Tahoon, "Synthesis of polymer-based magnetic nanocomposite for multi-pollutants removal from water," Polymers, vol. 13, no. 11, p. 1742, 2021.
[30] P. Koohi, A. Rahbar-kelishami, and H. Shayesteh, "Efficient removal of Congo red dye using $\mathrm{Fe} 3 \mathrm{O} 4 / \mathrm{NiO}$ nanocomposite: synthesis and characterization," Environmental Technology \& Innovation, vol. 23, article 101559, 2021.

[31] P. Arabkhani, H. Javadian, A. Asfaram, F. Sadeghfar, and F. Sadegh, "Synthesis of magnetic tungsten disulfide/carbon nanotubes nanocomposite ( $\mathrm{WS}_{2} / \mathrm{Fe}_{3} \mathrm{O}_{4} / \mathrm{CNTs}$ - NC) for highly efficient ultrasound-assisted rapid removal of amaranth and brilliant blue FCF hazardous dyes," Journal of Hazardous Materials, vol. 420, article 126644, 2021.

[32] A. Didehban, M. Zabihi, M. Faghihi, F. Akbarbandari, and H. Akhtarivand, "Design and fabrication of core-shell magnetic and non-magnetic supported carbonaceous metal organic framework nanocomposites for adsorption of dye," Journal of Physics and Chemistry of Solids, vol. 152, article 109930, 2021.

[33] A. Syed, A. M. Elgorban, A. H. Bahkali, and M. Sillanpää, "Visible-light sensitization and recombination delay through coupling $\mathrm{CaFe}_{2} \mathrm{O}_{4}$ on $\mathrm{Bi}_{2} \mathrm{O}_{3}$ nanocomposite for high performance photocatalytic and antibacterial applications," Surfaces and Interfaces, vol. 26, article 101336, 2021.

[34] P. Das and A. Debnath, "Reactive orange 12 dye adsorption onto magnetically separable $\mathrm{CaFe} 2 \mathrm{O} 4$ nanoparticles synthesized by simple chemical route: kinetic, isotherm and neural network modeling," Water Practice \& Technology, vol. 16, no. 4, pp. 1141-1158, 2021.

[35] M. Ghaedi, J. Tashkhourian, A. A. Pebdani, B. Sadeghian, and F. N. Ana, "Equilibrium, kinetic and thermodynamic study of removal of reactive orange 12 on platinum nanoparticle loaded on activated carbon as novel adsorbent," Korean Journal of Chemical Engineering, vol. 28, no. 12, pp. 2255-2261, 2011.

[36] M. Ghaedi, A. M. Ghaedi, F. Abdi, M. Roosta, R. Sahraei, and A. Daneshfar, "Principal component analysis-artificial neural network and genetic algorithm optimization for removal of reactive orange 12 by copper sulfide nanoparticles-activated carbon," Journal of Industrial and Engineering Chemistry, vol. 20, no. 3, pp. 787-795, 2014.

[37] S. Hajati, M. Ghaedi, F. Karimi, B. Barazesh, R. Sahraei, and A. Daneshfar, "Competitive adsorption of direct yellow 12 and reactive orange 12 on $\mathrm{ZnS}$ : Mn nanoparticles loaded on activated carbon as novel adsorbent," Journal of Industrial and Engineering Chemistry, vol. 20, pp. 564-571, 2014.

[38] M. Ghaedi, A. A. Pebdani, B. Sadeghian, R. Sahraei, A. Daneshfar, and C. E. L. A. L. Duran, "Synthesis and characterization of cadmium sulfide nanoparticle-loaded activated carbon as a novel adsorbent for efficient removal of reactive orange 12," Chemical Engineering Communications, vol. 200, no. 8, pp. 1071-1088, 2013.

[39] M. Ghaedi and R. Hosseininia, "Adsorption removal of reactive orange 12 from agueous solution by gold nanoparticule loaded on activated carbon: kinetic and equilibrium study," Iranian Chemical Society, vol. 16, 2013.

[40] A. K. Das, R. Govindaraj, and A. Srinivasan, "Structural and magnetic properties of sol-gel derived $\mathrm{CaFe}_{2} \mathrm{O}_{4}$ nanoparticles," Journal of Magnetism and Magnetic Materials, vol. 451, pp. 526-531, 2018.

[41] M. A. Hosseini, S. Malekie, and N. Ebrahimi, "The analysis of linear dose-responses in gamma-irradiated graphene oxide: Can FTIR analysis be considered a novel approach to examining the linear dose- responses in carbon nanostructures?," Radiation Physics and Chemistry, vol. 176, article 109067, 2020. 
[42] Y. Li, D. Pan, M. Zhang, J. Xie, and Z. Yan, "Ultrafine Co3O4embedded in nitrogen-doped graphene with synergistic effect and high stability for supercapacitors," RSC Advances, vol. 6, no. 54, pp. 48357-48364, 2016.

[43] C. Tan, J. Cao, A. M. Khattak et al., "High-performance tin oxide-nitrogen doped graphene aerogel hybrids as anode materials for lithium-ion batteries," Journal of Power Sources, vol. 270, pp. 28-33, 2014.

[44] M. Kaur, M. Kaur, D. Singh, A. C. Oliveira, V. K. Garg, and V. K. Sharma, "Synthesis of CaFe2O4-NGO nanocomposite for effective removal of heavy metal ion and photocatalytic degradation of organic pollutants," Nanomaterials, vol. 11, no. 6, p. 1471, 2021.

[45] H. Abd El-Wahab, A. Hassan, A. Naser, O. Fouad, A. El-Din, and O. Wahba, "Preparation and evaluation of nanosized mixed calcium iron oxide $\left(\mathrm{CaFe}_{2} \mathrm{O}_{4}\right)$ as high heat resistant pigment in paints," Pigment \& Resin Technology, vol. 44, no. 3, pp. 172-178, 2015.

[46] M. B. Tahir, M. Sagir, and K. Shahzad, "Removal of acetylsalicylate and methyl-theobromine from aqueous environment using nano-photocatalyst $\mathrm{WO}_{3}-\mathrm{TiO}_{2} @ g-\mathrm{C}_{3} \mathrm{~N}_{4}$ composite," Journal of Hazardous Materials, vol. 363, pp. 205-213, 2019.

[47] S. Noreen, U. Khalid, S. M. Ibrahim et al., " $\mathrm{ZnO}, \mathrm{MgO}$ and $\mathrm{FeO}$ adsorption efficiencies for direct sky blue dye: equilibrium, kinetics and thermodynamics studies," Journal of Materials Research and Technology, vol. 9, pp. 5881-5893, 2020.

[48] F. Ishtiaq, H. N. Bhatti, A. Khan, M. Iqbal, and A. Kausar, "Polypyrole, polyaniline and sodium alginate biocomposites and adsorption- desorption efficiency for imidacloprid insecticide," International Journal of Biological Macromolecules, vol. 147, pp. 217-232, 2020.

[49] R. Huang, Q. Liu, J. Huo, and B. Yang, "Adsorption of methyl orange onto protonated cross-linked chitosan," Arabian Journal of Chemistry, vol. 10, no. 1, pp. 24-32, 2017.

[50] Y. Liu, X. Liu, W. Dong, L. Zhang, Q. Kong, and W. Wang, "Efficient adsorption of sulfamethazine onto modified activated carbon: a plausible adsorption mechanism," Scientific Reports, vol. 7, no. 1, p. 12437, 2017.

[51] S. Afroze and T. K. Sen, "A review on heavy metal ions and dye adsorption from water by agricultural solid waste adsorbents," Water, Air, \& Soil Pollution, vol. 229, no. 7, p. 225, 2018.

[52] L. Lonappan, T. Rouissi, S. K. Brar, M. Verma, and R. Y. Surampalli, "An insight into the adsorption of diclofenac on different biochars: mechanisms, surface chemistry, and thermodynamics," Bioresource Technology, vol. 249, pp. 386394, 2018.

[53] T. J. M. Fraga, M. N. Carvalho, D. M. . S. M. Fraga, M. . C. L. da Silva, J. M. Ferreira, and M. A. da Motta Sobrinho, "Treated residue from aluminium lamination as adsorbent of toxic reactive dyes-a kinetic, equilibrium and thermodynamic study," Environmental technology, vol. 41, no. 6, pp. 669-681, 2020.

[54] A. Eltaweil, H. A. Mohamed, E. M. Abd El-Monaem, and G. El-Subruiti, "Mesoporous magnetic biochar composite for enhanced adsorption of malachite green dye: characterization, adsorption kinetics, thermodynamics and isotherms," Advanced Powder Technology, vol. 31, pp. 1253-1263, 2020.

[55] S. Kim, J. Lee, Y. Son, and M. Yoon, "Study of the dye adsorption kinetics ofMetal-OrganicFrameworks in aqueous media," Bulletin of the Korean Chemical Society, vol. 41, no. 8, pp. 843850, 2020.
[56] Y. Yuan, W. Zhan, F. Jia, and S. Song, "Multi-edged molybdenite achieved by thermal modification for enhancing $\mathrm{Pb}$ (II) adsorption in aqueous solutions," Chemosphere, vol. 251, article 126369, 2020.

[57] P. Sirajudheen, P. Karthikeyan, S. Vigneshwaran, and S. Meenakshi, "Synthesis and characterization of La(III) supported carboxymethylcellulose- clay composite for toxic dyes removal: Evaluation of adsorption kinetics, isotherms and thermodynamics," International Journal of Biological Macromolecules, vol. 161, pp. 1117-1126, 2020.

[58] M. Ghaedi, F. Karimi, B. Barazesh, R. Sahraei, and A. Daneshfar, "Removal of reactive orange 12 from aqueous solutions by adsorption on tin sulfide nanoparticle loaded on activated carbon," Journal of Industrial and Engineering Chemistry, vol. 19, no. 3, pp. 756-763, 2013.

[59] Y. Dong, M. Gao, Z. Song, and W. Qiu, “Adsorption mechanism of As(III) on polytetrafluoroethylene particles of different size," Environmental Pollution, vol. 254, article 112950, 2019.

[60] A. S. Abdulhameed, A.-T. Mohammad, and A. H. Jawad, "Application of response surface methodology for enhanced synthesis of chitosan tripolyphosphate/ $\mathrm{TiO}_{2}$ nanocomposite and adsorption of reactive orange 16 dye," Journal of Cleaner Production, vol. 232, pp. 43-56, 2019.

[61] M. Naushad, T. Ahamad, G. Sharma et al., "Synthesis and characterization of a new starch $/ \mathrm{SnO}_{2}$ nanocomposite for efficient adsorption of toxic $\mathrm{Hg}^{2+}$ metal ion," Chemical Engineering Journal, vol. 300, pp. 306-316, 2016.

[62] S. Rezania, M. A. Kamboh, S. S. Arian et al., "Nitrile-calixarene grafted magnetic graphene oxide for removal of arsenic from aqueous media: isotherm, kinetic and thermodynamic studies," Chemosphere, vol. 268, article 129348, 2021.

[63] Z. Ayazi, Z. M. Khoshhesab, F. F. Azhar, and Z. Mohajeri, "Modeling and optimization of adsorption removal of reactive orange 13 on the alginate-montmorillonite-polyaniline nanocomposite via response surface methodology," Journal of the Chinese Chemical Society, vol. 64, no. 6, pp. 627-639, 2017.

[64] N. S. Alsaiari, K. M. Katubi, F. M. Alzahrani et al., "Synthesis, characterization and application of polypyrrole functionalized nanocellulose for the removal of $\mathrm{Cr}(\mathrm{VI})$ from aqueous solution," Polymers, vol. 13, no. 21, p. 3691, 2021.

[65] N. S. Alsaiari, A. Amari, K. M. Katubi et al., "The biocatalytic degradation of organic dyes using laccase immobilized magnetic nanoparticles," Applied Sciences, vol. 11, no. 17, p. 8216, 2021. 